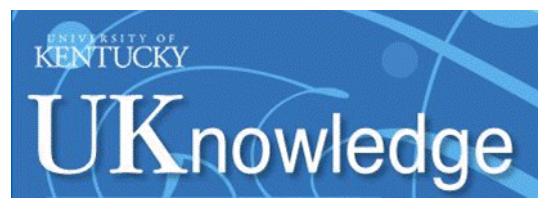

University of Kentucky

UKnowledge

\title{
Subcontracting and the Survival of Plants in the Road Construction Industry: A Panel Quantile Regression Analysis
}

\author{
Dakshina G. De Silva \\ Lancaster University, UK \\ Georgia Kosmopoulou \\ University of Oklahoma \\ Carlos Lamarche \\ University of Kentucky, clamarche@uky.edu
}

Follow this and additional works at: https://uknowledge.uky.edu/economics_facpub

Part of the Construction Engineering and Management Commons, Contracts Commons, Economics Commons, and the Government Contracts Commons

Right click to open a feedback form in a new tab to let us know how this document benefits you.

\section{Repository Citation}

De Silva, Dakshina G.; Kosmopoulou, Georgia; and Lamarche, Carlos, "Subcontracting and the Survival of Plants in the Road Construction Industry: A Panel Quantile Regression Analysis" (2017). Economics Faculty Publications. 6. https://uknowledge.uky.edu/economics_facpub/6

This Article is brought to you for free and open access by the Economics at UKnowledge. It has been accepted for inclusion in Economics Faculty Publications by an authorized administrator of UKnowledge. For more information, please contact UKnowledge@lsv.uky.edu. 


\section{Subcontracting and the Survival of Plants in the Road Construction Industry: A Panel Quantile Regression Analysis}

\section{Digital Object Identifier (DOI)}

https://doi.org/10.1016/j.jebo.2017.02.016

\section{Notes/Citation Information}

Published in Journal of Economic Behavior \& Organization, v. 137, p. 113-131.

(C) 2017 Elsevier B.V. All rights reserved.

This manuscript version is made available under the CC-BY-NC-ND 4.0 license https://creativecommons.org/licenses/by-nc-nd/4.0/.

The document available for download is the author's post-peer-review final draft of the article. 


\title{
Subcontracting and the Survival of Plants in the Road Construction Industry: A Panel Quantile Regression Analysis*
}

\author{
Dakshina G. De Silva \\ Lancaster University
}

\author{
Georgia Kosmopoulou \\ University of Oklahoma
}

\author{
Carlos Lamarche ${ }^{\dagger}$ \\ University of Kentucky
}

February 22, 2017

\begin{abstract}
This paper investigates how subcontracting parts of contracted work shapes entrants' success and survival. We find that newly developed quantile regression approaches can be adapted to study survival of firms competing for government contracts in road construction. The method is applied on a data set that includes patterns of firm entry, exit and auction related information. We find an apparent increase in the business life of firms who subcontract out part of their projects. In Texas, these subcontracting effects appear to be more pronounced for firms with few or no options outside the industry, and among firms who contract out part of their work to Disadvantaged Business Enterprises.
\end{abstract}

JEL Classification: C31, C41, D44, H57, L74.

Keywords: Entrants, procurement auctions, survival analysis, quantile regression.

${ }^{*}$ We are grateful to George Deltas, Tim Dunne, Matt Harding, Shakeeb Khan, Roger Koenker, Justin Marion, and Hisayuki Yoshimoto and participants at the 2nd conference on "Auctions, competition, regulation, and public policy" at Lancaster University and the 14th annual International Industrial Organization Conference for comments and suggestions. We are indebted to staff at the Texas Department of Transportation and Texas Workforce Commission for providing useful information. The authors obtained these data under an agreement of confidentiality and disclosure of the actual data is subject to certain restrictions. Any opinion, findings, and conclusions or recommendations expressed in this material are those of the authors and do not necessarily reflect the views of the National Science Foundation.

${ }^{\dagger}$ Dakshina G. De Silva is Professor at Lancaster University Management School, LA1 4YX, UK. Email: d.desilva@lancaster.ac.uk; Georgia Kosmopoulou was Program Director in Economics at the National Science Foundation when the work was completed, and is now Edith Kinney Gaylord Presidential Professor, University of Oklahoma, Norman, OK 73019. Email: georgiak@ou.edu; Carlos Lamarche is Gatton Endowed Associate Professor, University of Kentucky, Lexington, KY 40506. Email: clamarche@uky.edu. 


\section{Introduction}

Subcontracting allows a firm to unbundle contracts and share tasks with a network of business competitors, thus capitalizing on firm asymmetric strengths. The use of subcontractors varies across procurement auction settings, and the choices made affect entry and bidding. ${ }^{1}$ Little is known, however, about the effect of subcontracting on firm survival and whether it has a differential impact across competitors by their level of market experience. In this paper, we take a closer look at subcontracting and its effect on business duration, offering an estimation approach that can accommodate double censoring and endogenous covariates, commonly encountered in the analysis of panel duration data.

The firms we consider in our sample compete for public procurement contracts. The size of the public procurement activity in 2013 reached $13 \%$ of the GDP in the United States, $16 \%$ in the European Union and $12 \%$ across OECD countries, excluding procurement by state owned utilities. ${ }^{2}$ Most of these contracts are allocated via simple auction mechanisms. Theoretical research by Jeitschko and Wolfstetter (2002) and De Silva, Jeitschko and Kosmopoulou (2005) points to the fact that potential learning benefits for the winner create incentives for competitors to engage in risky behavior leading often to a serious bankruptcy problem (Leufkens, Peeters and Vermeulen (2010)). Under such competitive pressures, firms could contract out part of their work to ameliorate uncertainty and share information and expertise. Subcontracting allows bidders to control future costs by smoothing out workload obligations, leading possibly to a reduction in firms' information rents (Jeriorski and Krasnokutskaya, 2016). Transaction costs associated with subcontracting can often put significant upward pressure on project costs (Miller, 2014). In an effort to explore ramifications of the trade-off that exists between the uncertainty involved and the resulting profitability, we focus on firm survival at early stages of a firm's development, when entrants are likely to be inexperienced and uncertain about their costs but can take advantage of opportunities to subcontract out part of their business activity. We distinguish among firms based on opportunities for work outside road construction and whether they subcontract their work to Disadvantaged Business Enterprises (or DBEs) in response largely to policy driven

\footnotetext{
${ }^{1}$ See for example Gil and Marion (2013), Marion (2015), Moretti and Valbonesi (2015), and Branzoli and Decarolis (2015).

${ }^{2}$ The value of procurement activity by state owned utilities in countries of the Organization for Economic Cooperation and Development (OECD) amounts to $2-13 \%$ of their GDP.
} 
participation goals. ${ }^{3}$

This paper proposes a new quantile regression approach for doubly censored data to investigate the survival of establishments competing for goverment procurement contracts. Double censoring, or left-censoring and right-censoring, occurs often in the analysis of procurement data because the age of incumbents is not observed at the time of participation in auctions and information is limited by the length of the observation window. Lack of access to historical information about a population of interest is an issue in many longitudinal surveys related to unemployment duration, labor markets outcomes studied through recorded histories, educational outcomes and schooling durations. It is often a problem in firm market survival analysis across all industries and expansion through penetration in foreign markets. While most of the quantile regression literature focuses on the cross-sectional case, we propose a flexible semiparametric method for a panel duration quantile regression model with endogenous covariates. For example, Lin, He and Portnoy (2012), and Ji, Peng, Cheng and Lai (2012) offer semiparametric approaches for double censored data for cross-sectional models with exogenous covariates. ${ }^{4}$ Our methodology is built upon the approaches considered in Ji, Peng, Cheng and Lai (2012), Harding and Lamarche (2012), and Chernozhukov, Fernández-Val and Kowalski (2015).

We estimate a panel quantile model for establishments' survival in the market while controlling for unobserved firm heterogeneity as in Harding and Lamarche (2012). This is important since subcontracting activities are likely to be endogenous. The quantile approach is useful in examining the apparent increase in business life of conditionally young firms who subcontract out part of their active projects. We apply the method to a newly-constructed data set of establishments that allows an empirical investigation of the survival of plants in road construction. Our main result indicates that utilizing subcontractors that can share information and part of the uncertainty can have a positive effect on duration in business, in

\footnotetext{
${ }^{3}$ DBEs are defined as small businesses that are owned and controlled by members of a minority group including women-owned businesses and historically underrepresented businesses. Marion (2009, 2015) and De Silva, Dunne, Kosmopoulou, and Lamarche (2012) investigate the potential effects of DBE subcontracting on the cost of procurement contracting.

${ }^{4}$ Since Powell's (1986) seminal paper, there has been a growing literature on semiparametric censored models. For example see, Chen and Khan (2001), Horowitz and Lee (2004), Blundell and Powell (2007), Khan and Tamer (2007, 2009), Lee (2008), Honoré and de Paula (2010), among others. The quantile regression literature includes Portnoy (2003), Peng and Huang (2008), Galvao, Lamarche and Lima (2013) and a survey by Fitzenberger and Wilke (2006).
} 
particular at early stages of a firm's life. The empirical evidence suggests that those effects seem to be more pronounced for firms with limited business options outside road construction and those who employ DBE subcontractors. DBE subcontracting is often dictated by policy aiming to increase representation of underrepresented populations in business. Research has shown that more often than not these policies increase the cost of procurement (Marion 2009). Our results suggest that the employment of DBEs as subcontractors prolongs business life at low conditional quantiles, creating externalities significantly larger than those by non DBE firms. A possible explanation is that, in Texas, a DBE program appears to have encouraged the formation of a large number of DBE subcontractors who have gained experience in specific tasks and therefore can help firms to smooth out constraints of contracting.

These findings offer new evidence on the survival of plants in the road construction industry which is highly concentrated (see De Silva, Kosmopoulou and Lamarche, 2009). They also suggested that newly enacted programs similar to Mentor-protégé programs in Texas and Connect2DOT in Colorado, which have now been adopted in more than thirty states and provide firms the opportunity to create a network of subcontractors, can enhance their survival, particularly among entrants who are vital to the competitiveness of the market, and firms with limited opportunities outside road construction. The results complement the empirical studies analyzing the success of entrants in other manufacturing and service industries, retailing and agriculture (see Seim (2001), Dunne, Jensen and Roberts (2009), and Helfat and Lieberman (2002) for a review).

The paper is organized as follows. Section 2 discusses the theoretical model framing our statistical analysis. It also presents the quantile regression model and method. Section 3 describes the data, and it offers the main empirical results. Section 3 also examines the role of business opportunities outside the state procurement contracts on firm's survival. Section 4 has concluding remarks. Finally, Appendix A presents evidence on the small sample performance of the approach.

\section{Survival of Plants: Theory and Estimation}

The next section considers a dynamic framework that creates a link between government procurement contracting and the analysis of duration models in the spirit of Honoré and 
de Paula (2010). We focus on subcontracting activity which is widespread and has no institutional limit per contract. Later in Section 2.2, we propose a panel quantile estimator for the analysis of the survival of plants in the road construction industry which allows us to investigate the effect of subcontracting on conditionally low durations.

\subsection{Modeling Framework}

Firm $i$ (or establishment $i$, as in the empirical application) is in the construction industry primarily competing for contracts. The competition determines how long it will continue being active in business by selecting an optimal continuation strategy that leads to an exit time $T$. The firm also decides whether to subcontract out part of a project. This is motivated by the fact that in our data, which is described in Section 3.1, 87.37\% of prime contractors subcontract out a percentage of the contracted tasks and the number of subcontractors in government procurement projects ranges from 0 to 35 . On average, $20.43 \%$ of a contract's value is subcontracted out.

Consider $\pi$ to be the profit function of a firm consisting of the net payoff from contracting activity, and the payoff from complementary business activity. The profit related to contracting activity, $\pi_{C}$, is a function of auction, bidder and rival characteristics $\mathbf{x} \in \mathbf{X} \subset \mathbf{R}^{p_{1}}$, and the size of firm and involvement in subcontracting activity captured by the vector $\mathbf{s} \in \mathbf{S} \subset \mathbf{R}^{p_{2}}$. In our econometric specification introduced in section $3, p_{2}=2$. At any time $t$, therefore, the profit function of a representative firm takes the following form

$$
\pi(\mathbf{x}, \mathbf{s}, t)=\pi_{C}(\mathbf{x}, \mathbf{s}, t)+A(t)
$$

where $A(t)$ represents an outside option assumed later to be $A=0$ to distinguish firms by their dependence on road construction procurement. We also assume that $\pi_{C}(\mathbf{x}, \mathbf{s}, t)=$ $V(\mathbf{x}, \mathbf{s}, t, \theta(\mathbf{x}, \mathbf{s}))-C(\mathbf{x}, \mathbf{s}, t, f)$, where $V(\mathbf{x}, \mathbf{s}, t, \theta(\mathbf{x}, \mathbf{s})):=W(\mathbf{x}, \mathbf{s}) \theta(\mathbf{x}, \mathbf{s}) \phi(t)$ is the ex post value of a contract to a firm, $W(\mathbf{x}, \mathbf{s})$ is the payoff related in part to auction and bidders characteristics, and $\theta(\cdot, \cdot)$ is a firm specific productivity index that can enhance the profit from procurement contracting. We assume $\phi(t)>0$ for $t>1$ and $\phi(0)=0$. The term $C(\mathbf{x}, \mathbf{s}, f, t)$ is a cost function related to bidder characteristics, project characteristics, size and subcontracting opportunities, a fixed operating cost, $f$, and $t$. We let $C(\mathbf{x}, \mathbf{s}, f, t)=$ $h(\mathbf{x}, \mathbf{s}, f) \psi(t)$ where $\psi$ is a function associated with changes in costs through time $(\psi(t)>0$ 
with $\psi(0)=0)$. Finally, we assume, for simplicity, the outside option $A(t)=A \psi(t)$.

Assuming an exponential discount rate $\rho$, we can express the net profit from road construction business until time $t$ as

$$
\int_{0}^{t} \pi_{C}(\mathbf{x}, \mathbf{s}, z) e^{-\rho z} d z=\int_{0}^{t}[W(\mathbf{x}, \mathbf{s}) \theta(\mathbf{x}, \mathbf{s}) \phi(z)-h(\mathbf{x}, \mathbf{s}, f) \psi(z)] e^{-\rho z} d z .
$$

Then the cumulative profit across activities is

$$
\int_{0}^{t}[W(\mathbf{x}, \mathbf{s}) \theta(\mathbf{x}, \mathbf{s}) \phi(z)-h(\mathbf{x}, \mathbf{s}, f) \psi(z)] e^{-\rho z} d z+\int_{0}^{t} A \psi(z) e^{-\rho z} d z .
$$

Conditional on size and subcontracting decisions, optimizing behavior with respect to $t$ requires that the firm will continue to be in business as long as the benefit of being active at time $t$ exceeds the cost and the value of the outside option, i.e.,

$$
W(\mathbf{x}, \mathbf{s}) \theta(\mathbf{x}, \mathbf{s}) \phi(T)=(h(\mathbf{x}, \mathbf{s}, f)-A) \psi(T) .
$$

This first order condition determines the optimal timing $T$ for exit. Conditional on the optimal timing decision, the firm will choose $\mathbf{s}$ to maximize the value of the objective function subject to the constraint that $\mathbf{s}$ depends upon $\mathbf{w}$ which is defined as a vector of exogenous variables that do not affect a firm's decision to exit and exogenous restrictions related to the use of disadvantaged business enterprises as subcontractors based on government set goals. These variables will serve as instruments in our econometric specification and will be discussed at length in section 3.2 within the context of our empirical application. Specifically the objective is to

$$
\max _{\mathbf{s} \in \mathbf{S}} \Pi(T(\mathbf{s}))=\max _{\mathbf{s} \in \mathbf{S}}\{W(\mathbf{x}, \mathbf{s}) \Phi(T(\mathbf{s})) \theta(\mathbf{x}, \mathbf{s})-(h(\mathbf{x}, \mathbf{s}, f)-A) \Upsilon(T(\mathbf{s}))+\lambda(\mathbf{s}-\zeta(\mathbf{w}))\}
$$

where $\lambda$ is a Lagrange multiplier, $\zeta(\cdot)$ is a known smooth function, $\Phi(T)=\int_{0}^{T} \phi(z) e^{-\rho z} d z$, and $\Upsilon(T)=\int_{0}^{T} \psi(z) e^{-\rho z} d z$. We shall consider this more general case in section 3.3, although in what follows, we concentrate on the case of no outside business opportunities by assuming $A=0$.

Let $\phi(T) / \psi(T)=\xi(T)$. Under mild conditions, these two optimization problems produce a system of interdependent equations that can be written as:

$$
\begin{aligned}
T & =\xi^{-1}(h(\mathbf{x}, \mathbf{s}, f) / W(\mathbf{x}, \mathbf{s}) \theta(\mathbf{x}, \mathbf{s})) \\
\mathbf{s} & \equiv \arg \max \Pi(T(\mathbf{s}), \zeta(\mathbf{w}))
\end{aligned}
$$


It follows from equation (2.6) that

$$
\ln \xi(T)=-\ln W(\mathbf{x}, \mathbf{s})-\ln \theta(\mathbf{x}, \mathbf{s})+\ln h(\mathbf{x}, \mathbf{s}, f)
$$

The economic model in (2.8) leads to a simple, yet convenient statistical model that fits within a class of duration models. For instance, appropriate choices for $\xi(T)$ and $W(\mathbf{x}, \mathbf{s})$ lead to the Accelerated Failure Time (AFT) model. ${ }^{5}$ Following standard practice, we assume that the ex post value of the contract for a firm is $W(\mathbf{x}, \mathbf{s})=\exp \left(\mathbf{s}^{\prime} \gamma+\mathbf{x}^{\prime} \beta\right)$. Moreover, we assume that issues associated with possible dependence between a firm's unobserved heterogeneity and $(\mathbf{x}, \mathbf{s})$ can be addressed by controlling for a duration-invariant omitted variable, $\alpha:=-\ln \theta(\mathbf{x}, \mathbf{s})$. Under these assumptions, a version of the model presented in equation (2.8) can be written as

$$
M(T)=\mathbf{s}^{\prime} \gamma+\mathbf{x}^{\prime} \beta+\alpha+u,
$$

where $M(\cdot)$ is a monotone function, in this case the logarithmic function, and $u$ is an error term distributed as $F_{u}$ with a conditional variance that depends on $\mathbf{x}$ and $\mathbf{s}$. Note that the error term contains components of the latent cost, and these factors are correlated with the vector $\mathbf{s}$ as in equation (2.7) conditional on individual effects. Lastly, we note that the variable time to exit the market, $T$, in equation (2.9) is not fully observed as we observe only,

$$
Y=\max \{L, \min \{T, U\}\}
$$

where the variable $Y$ represents the standard censored response variable, $L$ denotes leftcensoring time, and $U$ denotes right-censoring time. In our application, $L$ is zero for entrants and the age of the firm for incumbents and $U$ denotes the time period at which we cease to observe firm activity whether it has exited or not.

Based on this model, we estimate the following quantile regression function:

$$
Q_{M(T)}(\tau \mid \mathbf{x}, \mathbf{s}, \alpha)=\mathbf{s}^{\prime} \gamma(\tau)+\mathbf{x}^{\prime} \beta(\tau)+\alpha(\tau)
$$

where $Q_{M(T)}(\tau \mid \mathbf{x}, \mathbf{s}, \alpha)=\inf \{y: \operatorname{Pr}(Y<y \mid \mathbf{x}, \mathbf{s}, \alpha) \geq \tau\}$ is the $\tau$-th conditional quantile function given $\left(\mathbf{s}^{\prime}, \mathbf{x}^{\prime}, \alpha\right)$ and $\tau \in(0,1)$ is a quantile of the conditional survival times distribution. ${ }^{6}$

\footnotetext{
${ }^{5}$ See Lancaster (1990), Lee (2008) and Honoré and de Paula (2010).

${ }^{6}$ The structural parameter, $\gamma(\tau)$, can be interpreted as representing the effect of $\mathbf{s}$ on the $\tau$-th conditional
} 
Quantiles are equivariant to monotone transformations, therefore we can write the previous model as $Q_{M(T)}(\tau \mid \mathbf{x}, \mathbf{s}, \alpha)=M\left(Q_{T}(\tau \mid \mathbf{x}, \mathbf{s}, \alpha)\right)$. Thus, the survival times distribution can be expressed as $Q_{T}(\tau \mid \mathbf{x}, \mathbf{s}, \alpha)=\exp \left\{\mathbf{s}^{\prime} \gamma(\tau)+\mathbf{x}^{\prime} \beta(\tau)+\alpha(\tau)\right\}$.

It is important to emphasize that we concentrate our attention on a quantile version of equation (2.6) and, as implied by equation (2.7), some elements of the vector $\mathbf{s}$ might not be exogenous, even if we condition on firm unobserved heterogeneity, $\alpha$. For instance, the size of a new establishment, or subcontracting might not be determined independently of whether the firm stayed in business as suggested by (2.7). To deal with the potential endogeneity of the independent variables, we adopt the control variable approach proposed by Chernozhukov, Fernández-Val and Kowalski (2015). It basically adds a variable in the regression so that conditional on it, regressors are not correlated with the error term of the model. Their approach works in the spirit of Blundell and Powell (2007), although it allows for a flexible non-additive first stage specification. The control variable is defined as,

$$
\mathbf{v}=\psi_{0}(\mathbf{s}, \mathbf{x}, \alpha, \mathbf{w}) \equiv F_{\mathbf{s}}(\mathbf{s} \mid \mathbf{x}, \alpha, \mathbf{w}) \equiv Q_{\mathbf{s}}^{-1}(\mathbf{s} \mid \mathbf{x}, \alpha, \mathbf{w})
$$

where $\psi_{0}(\cdot)$ is a control function, $\mathbf{w}$ is a vector of instruments, $F_{\mathbf{s}}$ is the conditional distribution of $\mathbf{s}$, and $Q_{\mathbf{s}}$ is the conditional quantile function of $\mathbf{s}$. Note that $F_{\mathbf{s}}$ or $Q_{\mathbf{s}}$ can be estimated by any parametric or semiparametric method. Therefore, $P\left(T \leq Q_{T}(\tau \mid \mathbf{s}, \mathbf{x}, \alpha) \mid \mathbf{v}, \mathbf{x}, \alpha\right)$ is equal to the quantile $\tau$. This assumption is standard in the quantile regression literature and is equivalent to require that $u(\tau)=T-Q_{T}(\tau \mid \mathbf{s}, \mathbf{x}, \alpha)$ has zero $\tau$-th quantile conditional on $\mathbf{v}, \mathbf{x}$, and $\alpha .^{7}$

\subsection{Estimation}

To obtain consistent and unbiased estimates of the effect of subcontracting on the conditional duration distribution, it is clear that we need to address issues associated with double censoring and endogenous independent variables at the same time. This section proposes

quantile function of the response variable while controlling for heterogeneity, say $\alpha$. This model can be viewed as a conditional model. There are other conditional models available in the quantile regression literature and we refer the reader to Kim and Yang (2011) for additional discussion on marginal and conditional quantile regression models. Moreover, it is also different than the unconditional quantiles work by Firpo, Fortin, and Lemieux (2009) and Frölich and Melly (2013).

${ }^{7}$ It can also be considered $\mathbf{s}=g(\mathbf{w})+\mathbf{v}$, where $g(\mathbf{w})$ may be a non-parametric function, and $\mathbf{v}$ is an error term that is not independent from $u$. Blundell and Powell (2007) approach is similar to the one proposed by Chen and Khan (2001), which is based on a non-parametric function $\Lambda(\mathbf{v})$ defined for $\mathbf{v} \equiv \mathbf{s}-g(\mathbf{w})$. 
a semiparametric estimation approach for the quantile regression model (2.11) that encompasses the control variable in (2.12) and double censoring as in (2.10).

Consider, for simplicity, a sample of $n$ firms observed $m$ times. ${ }^{8}$ As in Harding and Lamarche (2012), we find the argument that minimizes a quantile regression objective function with individual effects. In contrast to existing work however, we augment the model by a control variable. ${ }^{9}$ Let $\mathbf{X}_{i j}=\left(\mathbf{s}_{i j}^{\prime}, \mathbf{x}_{i j}^{\prime}, \mathbf{z}_{i}^{\prime}, \hat{\mathbf{v}}_{i j}^{\prime}\right)^{\prime}$ where $\mathbf{z}_{i}$ is a vector that indicates firm $i$, and $\boldsymbol{\Psi}\left(\tau_{k}\right)=\left(\gamma\left(\tau_{k}\right)^{\prime}, \beta\left(\tau_{k}\right)^{\prime}, \alpha\left(\tau_{k}\right)^{\prime}, \lambda\left(\tau_{k}\right)^{\prime}\right)^{\prime}$. The estimator of the control variable (2.12) is based on $\mathbf{v}_{i j}=Q_{V}^{-1}\left(\mathbf{s}_{i j}-g\left(\mathbf{x}_{i j}, \mathbf{z}_{i}, \mathbf{w}_{i j}\right)\right)$ where $g(\cdot)$ is a known linear parametric function and the control variable $\mathbf{v}_{i j}$ can be estimated by the empirical cumulative distribution function of the least squares residuals. ${ }^{10}$ Our estimator for $\boldsymbol{\Psi}(\tau)$ is then defined as follows:

$$
\hat{\mathbf{\Psi}}(\tau)=\arg \min _{\boldsymbol{\Psi} \in \boldsymbol{\Theta}} \sum_{i=1}^{n} \sum_{j=1}^{m}\left(\log \left(Y_{i j}\right)-\mathbf{X}_{i j}^{\prime} \mathbf{\Psi}(\tau)\right)\left(\vartheta_{i j}(\tau)-\delta_{i j} I\left(\log \left(Y_{i j}\right)-\mathbf{X}_{i j}^{\prime} \mathbf{\Psi}(\tau)<0\right)\right)
$$

where $\delta_{i j}$ equals 1 if $L_{i j} \leq T_{i j} \leq U_{i j}$ and 0 otherwise and,

$$
\vartheta_{i j}(\tau)=\sum_{k=0}^{q-1} I\left(Y_{i j} \geq \exp \left(\mathbf{X}_{i j}^{\prime} \Psi\left(\tau_{k}\right)\right)>L_{i j}\right)\left(H\left(\tau_{k+1}\right)-H\left(\tau_{k}\right)\right),
$$

The solution of (2.13), $\hat{\mathbf{\Psi}}(\tau)$, is called the $\tau$-th panel quantile regression estimator for doubly censored data (PQDC). Naturally, in the case of censored data and exogenous covariates, one can estimate the model by solving (2.13) while replacing $\mathbf{X}_{i j}$ by $\left(\mathbf{s}_{i j}^{\prime}, \mathbf{x}_{i j}^{\prime}, \mathbf{z}_{i}^{\prime}\right)^{\prime}$. We employ this estimator in Section 3.2 and we compare the results with the results obtained by the PQDC estimator, $\hat{\Psi}(\tau)$.

The standard error of $\hat{\boldsymbol{\Psi}}(\tau)$ in the next Section 3 is obtained by the bootstrap procedure proposed by Jin, Ying and Wei (2001) and investigated in Ma and Kosorok (2005). This procedure works under fairly general conditions and can accommodate within block corre-

\footnotetext{
${ }^{8}$ The estimation approach proposed in this section can be naturally applied to different datasets including balanced and unbalanced panels. In Section 3.2, we estimate the quantile model using $m$ firms with $n_{j}$ establishments. The implication is that the number of establishments of firm $j$ can be different than the number of establishments of firm $k$.

${ }^{9}$ When $L_{i j}=0$ for all $(i, j)$ and instruments are used instead of control variables, our proposed estimator is identical to Harding and Lamarche's (2012) estimator. While an instrumental variable approach to panel duration quantile models with a large number of firms may be regarded by applied researchers as computationally demanding, the approach proposed in this paper solves a relatively simpler linear programming problem that performs extremely well in large size applications.

${ }^{10}$ See Chernozhukov, Fernández-Val and Kowalski (2015) for alternative specifications and estimators.
} 
lation. ${ }^{11}$ Because it maintains the endogenous structure of the model, it can be extended to include the use of a control function to address the potential endogeneity of size and subcontracting activities.

\section{Survival of firms in the construction industry}

In this section, we use a sample of entrants and incumbents to study how procurement auctions shape the survival of firms in the road construction industry. We first perform, in Appendix A, a brief simulation study to investigate the performance of the proposed estimator. We then employ the estimation procedure developed in this paper and report the results in Section 3.2. Finally, we perform a series of robustness checks, considering alternative samples and approaches. Our main results highlight the impact that subcontracting out can have on duration in business. The proposed approach which has excellent finite sample properties as shown in Appendix A is useful in uncovering the increase in the conditional business life of young entrants who engage in subcontracting.

\subsection{A Description of the data}

Our firm-level data were obtained from two sources: the Texas Department of Transportation (TxDOT) and the Texas Workforce Commission. The data that contain information on bidding activity for highway construction contracts were obtained from TxDOT. They span the period between July 1999 and December 2006. All projects are auctioned off using a firstprice sealed-bid format. The data set contains information on project types, the engineer's cost estimate for each project, the number of bidders that requested plans, the number of bids submitted per project, the winning bidders, and the winning bids. It also contains the location and complexity of each project and the number of days until its completion. A detailed description of the initial information that was collected and the variables that were subsequently constructed are in Table B.1 in Appendix B. The data set also provides the names of subcontractors for the winning bidders and corresponding negotiated subcontractor

\footnotetext{
${ }^{11}$ Jin, Ying and Wei (2001) and Ma and Kosorok (2005) suggest drawing independent variables from a non-negative distribution with mean 1 and variance 1 (i.e., exponential or Gamma distribution) to perturb the objective function. In our application, we obtain $\Psi^{*}$ as the argument that minimizes a perturbed (2.13). We reiterate this procedure $B$ times to obtain a large sample of realizations $\left\{\boldsymbol{\Psi}_{b}^{*}\right\}_{b=1}^{B}$. For a given quantile, we can obtain the variance of $\hat{\boldsymbol{\Psi}}(\tau)$ by the sample variance of $\left\{\boldsymbol{\Psi}_{b}^{*}\right\}_{b=1}^{B}$.
} 


\begin{tabular}{lccc}
\hline Variable & All firms & Incumbents & Entrants \\
\hline Number of firms that held plans & 993 & 629 & 364 \\
Number of establishments (branches) & 1275 & 751 & 524 \\
Total number of bids & & & \\
& 6,998 & 5,727 & 1,271 \\
Total number of wins & {$[7.05]$} & {$[9.10]$} & {$[3.49]$} \\
& 1,668 & 1,375 & 293 \\
Number of firms that submit at least a bid & {$[1.68]$} & {$[2.19]$} & {$[0.80]$} \\
& 540 & 394 & 146 \\
Number of firms that at least won once & {$[0.54]$} & {$[0.63]$} & {$[0.40]$} \\
& {$[0.341$} & 267 & 74 \\
Relative bid & 1.077 & {$[0.42]$} & {$[0.20]$} \\
& $(0.249)$ & $(0.247)$ & 1.079 \\
Relative winning bid & 0.970 & 0.974 & 0.946 \\
& $(0.177)$ & $(0.176)$ & $(0.181)$ \\
Number of employees & 75.935 & 70.110 & 92.567 \\
& $(247.727)$ & $(198.236)$ & $(265.410)$ \\
Number of months in the market & 51.579 & 64.855 & 32.553 \\
& $(35.577)$ & $(34.383)$ & $(27.788)$ \\
\hline
\end{tabular}

Table 1: Descriptive statistics for the TXDOT-QCEW data. The sample includes existing firms (Incumbents) and new firms that entered the market in the period July 1999-December 2006 (Entrants). Relative Bid is defined as bid divided by the engineer's cost estimate and Relative winning bid as winning bid divided by the engineer's cost estimate. Statistics scaled by the number of firms are shown in brackets and standard deviations are in parentheses.

dollar values. This allows us to identify primary bidders who have initially participated as subcontractors in TxDOT auctions.

Establishment-level monthly employment and quarterly wage data for Texas establishments were obtained from the Texas Workforce Commission's Quarterly Census of Employment and Wages (QCEW) data base. This data base, as required under the Texas unemployment insurance (UI) program, provides establishment-specific monthly employment and quarterly total wages. It also includes each firm's business start-up date, the specific location of the establishment, and the six-digit North American Industry Classification System (NAICS) code. Separate establishments (branches or plants) of the same firm are identified and reported in separate records. This allows us to identify firm level expansions or contractions (increase or decrease in number of branches and employment). These permanent 

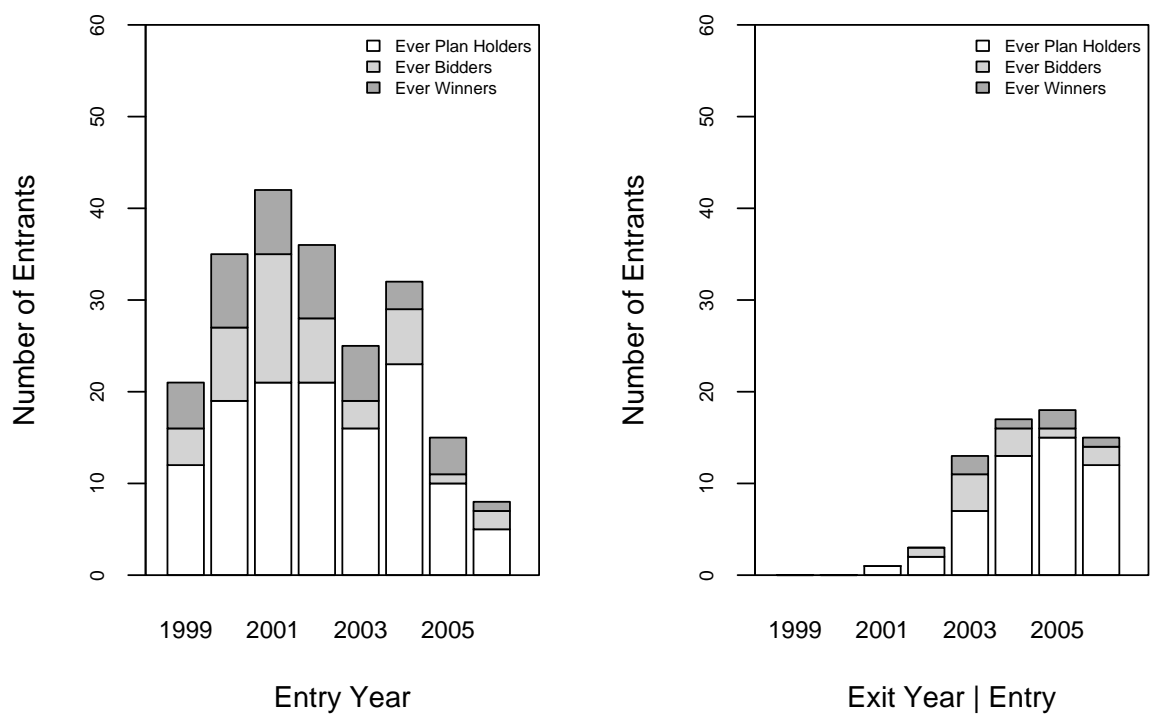

Figure 1: Frequencies for the number of entrants and exitors. The $x$-axis on the left panel considers the year of entry for entrants after July 1999. The x-axis on the right panel considers the year of exit for firms that entered the market after July 1st, 1999. The shaded areas denote firms' activities related to the procurement auctions.

or temporary expansions (contractions) could be due to the natural rate of firm growth (declines) or to absorption of a temporary shock due to winning (completion of) a long term project in a distant location from the main office. The appearance of a new Employer Identification Number (EIN) and firm start-up date signifies entry and disappearance of an EIN record signifies exit. This is similar to the definition used by Baldwin and Gorecki (1991) and Dunne, Roberts and Samuelson (1988)). ${ }^{12}$ In a similar way, we also use the establishment start date and employment patterns to identify entry and exit. However, our data suggest that bids are generated from the main office and not from branches.

Table 1 reports information on all firms that held plans (plan holders) during this period. ${ }^{13}$ A unique characteristic of this market is that there are a large number of plan

\footnotetext{
${ }^{12}$ The data allows us to identify changes in the names of firms. Those changes should not be counted as exit (Dunne et al. 1988). Moreover, we can identify horizontal mergers.

${ }^{13}$ Any contractor considering to bid on a project must request a plan from the state. The list of plan holders defines the potential competitors in an auction. The plan holder list is public information and becomes available to all bidders.
} 
Single establishment

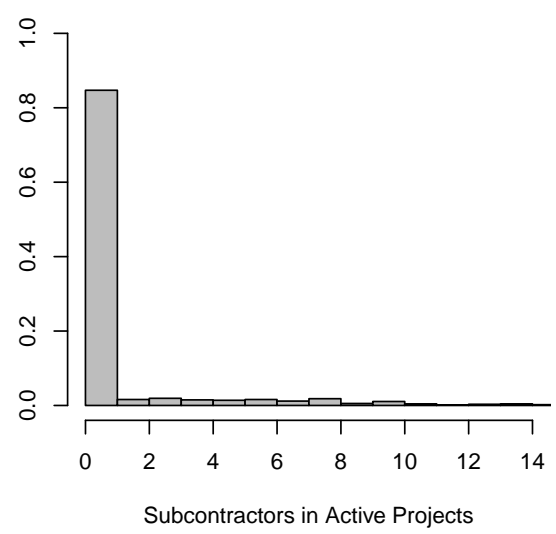

Multiple establishments

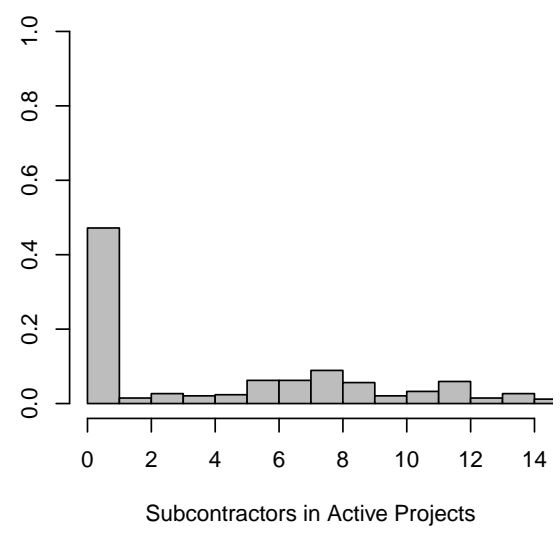

Single establishment

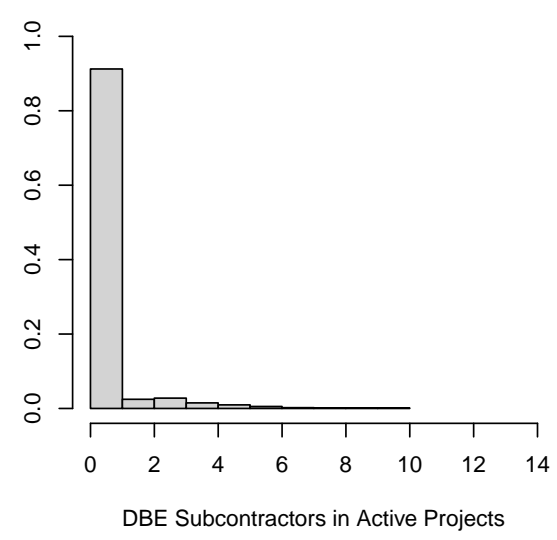

Multiple establishments

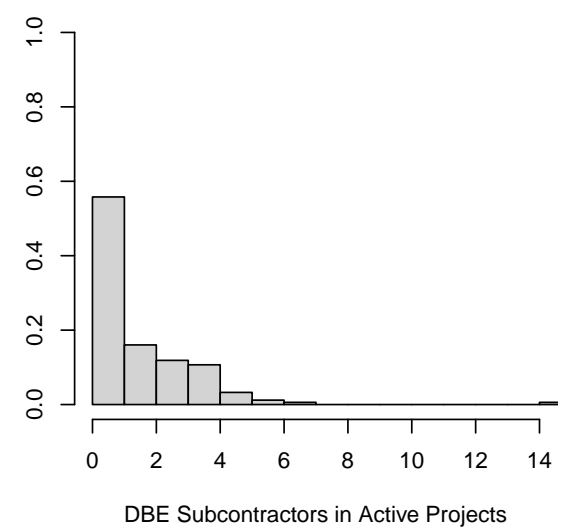

Figure 2: Frequencies for the number of subcontractors in active projects. The left panels presents the number of subcontractors and the right panels the number of Disadvantaged Business Enterprises (or DBEs) Subcontractors. 
holders that are capable of intensifying competitive pressures intermittently through the bidding process. There are 993 different plan holders and 540 bidders in this data set. Table 1 also provides information on relative bids and relative winning bids which are bids that are normalized by their engineering cost estimates. The average relative bid is 1.077 and the average relative winning bid is 0.970 . These incumbent firms had about 70 employees per branch and on average, survived about 64 month. Column 3 reports the summary statistics for entrants. Entrants are bidding lower and are winning with more aggressive bids. We observe that there are 364 entrants and 74 of them are contractors in the period of analysis. They stay in the market for about half of the life of incumbents.

The sample of entrants include 214 plan holders and 41 firms (with potentially many branches) that won a project at least once in their early stages. Using this sample of entrants, Figure 1 shows the empirical distributions of firms' entry and exit. Note that these estimates do not suffer from biases arising from left-censoring. The first panel presents the number of plan holders that enter the market. Approximately 41 percent of firms became bidders and 20 percent became winners in the period of analysis. We see that the number of firms entering the market increased in the period 1999-2001, and had a decreasing trend after 2001. Nevertheless, the year of entry does not seem to be a critical determinant of the probability of winning. While 20 percent became contractors in the period 1999-2001, 19 percent became contractors in the period after. The second panel presents the number of plan holders that exited the market in the same period of analysis. The evidence indicates that no firm that entered the market in either 1999 or 2000 exited the market in those years.

As illustrated in Figure 2, there are high- and low-subcontracting establishments and the number of subcontractors in active projects depends on the number of branches per firm. The total number of subcontractors ranges from 0 to 35, with a mean of 1.86 subcontractors in active projects. ${ }^{14}$ To make Figure 2 clearer, we limit the number of subcontractors in active projects to 14 . The panels also shows that high-subcontractor establishments are typically part of a firm with multiple establishments. When we focus on Disadvantaged Business Enterprises, the number of DBE subcontractors is naturally smaller. Nevertheless, 2555

\footnotetext{
${ }^{14}$ We observe subcontractor information when a firm wins. Any subcontractor responsible for working on the project has to be identified and listed with the Texas Department of Transportation. Unfortunately we do not see subcontractors subcontracting. From what we know when a winner subcontracts, that portion has to be completed by the subcontractors that are listed.
} 

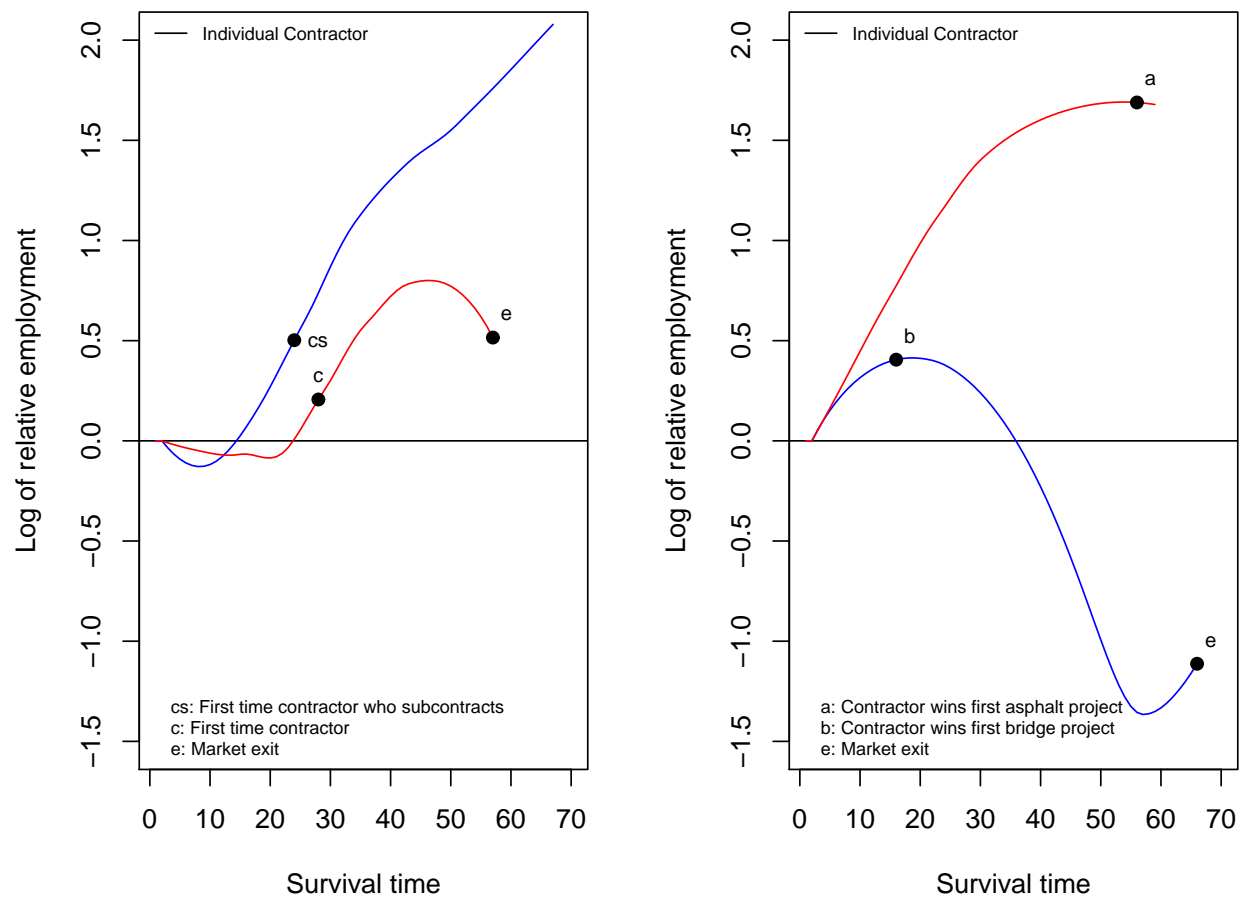

Figure 3: Profile of contractors' relative size. The y-axis shows the logarithm of employment relative to initial employment and the $x$-axis the number of months from establishment in business. The letters $c s$ and $c$ indicate events in the firms' life related to the procurement auctions: cs denotes first time contractor who subcontract out part of the project, and $c$ indicates first win as primary contractor who does not subcontract out part of the project. The letters a indicates asphalt, $b$ denotes bridge, and e denotes exit time.

projects have some DBE goals. Such goals are set on federal projects only. The average DBE goal is 3.40 of the contracted value across all federal projects and 6.31 across all projects with actual DBE goals. It is interesting to see that more than 90 percent of single-establishment firms, which are typically entrant firms, do not use DBE subcontracting.

A graph on business activity of individual contractors can provide intuition about the role of procurement auctions on firm survival. Figure 3 considers four contractors and offers a cursory look at employment patterns as a function of time. These firms were selected for their value in emphasizing activities and survival paths that later prove to be quite representative. The panel to the left illustrates the role of subcontracting on duration in 
business. The longitudinal dimension of the data tentatively ascribes the apparent influence of subcontracting out part of the first contract on business duration. Although the firms won their first projects at a similar age, only the company that subcontracted part of its project (indicated by the letters cs) seems to have grown over time. The right panel in Figure 3 focuses on relative risks associated with involvement in different type of projects. As seen on the graph, the contractor who did asphalt work had a steady employment growth despite the fact that contracting activity for TxDOT started only after the first four and a half years in business. The size of the entrant in bridge work increased until the first project was won (indicated by the letter b). Immediately after that, the size of the company decreased leading eventually to market exit (denoted by e). For this firm survival in business may have been associated with uncertainty induced by the projects undertaken and lack of outside business options that can affect the timing of the first win.

\subsection{Main Empirical Results}

We begin estimating a model for survival times using standard approaches. The results are shown in Table 2. The dependent variable is duration in the market for an establishment and the main independent variables are average number of employees (size) of the plant during the duration of the spell, a binary variable indicating whether the establishment is an entrant, the cost index of active projects, and the average number of subcontractors that a firm seeks out. In all the models estimated in this section, we include capacity utilization and backlog variables. The cost index is based on a composite indicator that covers the unit costs of excavation, resurfacing and construction. It mainly reflects exogenous cost changes for materials needed to complete highway projects. The table shows quantile regression results, the fixed effects quantile regression estimator as in Koenker (2004), and quantile regression results for a model with censored data as in Peng and Huang (2008). We also show results obtained by Powell's (1984) CLAD estimator which is designed to address right censoring in a cross-sectional model with exogenous variables. For completeness, the table shows classical OLS and fixed effects results. The interested reader can find additional details on how the variables were constructed in Appendix B.

One might argue about the validity of the results presented in Table 2. Several issues are worth mentioning: (i) the dependent variable is left-censored for incumbents since we 


\begin{tabular}{|c|c|c|c|c|c|c|}
\hline \multirow[t]{2}{*}{ Variables } & \multicolumn{5}{|c|}{ Quantiles } & \multirow[t]{2}{*}{ Mean } \\
\hline & 0.10 & 0.25 & 0.50 & 0.75 & 0.90 & \\
\hline & \multicolumn{5}{|c|}{ Pooled Quantile Regression } & OLS \\
\hline \multirow[t]{2}{*}{ Size } & -0.766 & -0.619 & -0.173 & 0.000 & 0.000 & -0.486 \\
\hline & $(0.044)$ & $(0.039)$ & $(0.035)$ & $(0.009)$ & $(0.004)$ & $(0.022)$ \\
\hline \multirow[t]{2}{*}{ Entrant } & -0.540 & -0.773 & -0.769 & -0.341 & -0.174 & -0.699 \\
\hline & $(0.161)$ & $(0.140)$ & $(0.127)$ & $(0.032)$ & $(0.014)$ & $(0.079)$ \\
\hline \multirow[t]{2}{*}{ Cost Index } & -0.024 & -0.024 & -0.025 & -0.029 & -0.028 & -0.026 \\
\hline & $(0.005)$ & $(0.004)$ & $(0.004)$ & $(0.001)$ & $(0.000)$ & $(0.003)$ \\
\hline \multirow[t]{2}{*}{ Subcontracting } & -0.024 & -0.108 & -0.075 & -0.015 & 0.000 & -0.034 \\
\hline & $(0.030)$ & $(0.026)$ & $(0.024)$ & $(0.006)$ & $(0.003)$ & $(0.015)$ \\
\hline & \multicolumn{5}{|c|}{ Panel Quantile Regression } & $\mathrm{FE}$ \\
\hline \multirow[t]{2}{*}{ Size } & 0.083 & 0.070 & 0.013 & 0.000 & 0.000 & 0.076 \\
\hline & $(0.043)$ & $(0.018)$ & $(0.020)$ & $(0.028)$ & $(0.020)$ & $(0.022)$ \\
\hline \multirow[t]{2}{*}{ Entrant } & -0.791 & -0.542 & -0.607 & -0.271 & -0.129 & -0.348 \\
\hline & $(0.115)$ & $(0.047)$ & $(0.053)$ & $(0.074)$ & $(0.053)$ & $(0.194)$ \\
\hline \multirow[t]{2}{*}{ Cost Index } & -0.017 & -0.020 & -0.018 & -0.022 & -0.027 & -0.018 \\
\hline & $(0.003)$ & $(0.001)$ & $(0.002)$ & $(0.002)$ & $(0.002)$ & $(0.005)$ \\
\hline \multirow[t]{3}{*}{ Subcontracting } & 0.002 & 0.002 & 0.001 & 0.000 & 0.003 & 0.022 \\
\hline & $(0.023)$ & $(0.010)$ & $(0.011)$ & $(0.015)$ & $(0.011)$ & $(0.013)$ \\
\hline & \multicolumn{5}{|c|}{ Censored Quantile Regression } & CLAD \\
\hline \multirow[t]{2}{*}{ Size } & 0.078 & 0.000 & 0.000 & 0.000 & 0.000 & -0.073 \\
\hline & $(0.597)$ & $(0.000)$ & $(0.000)$ & $(0.000)$ & $(0.000)$ & $(0.005)$ \\
\hline \multirow[t]{2}{*}{ Entrant } & -0.523 & -0.459 & -0.261 & -0.170 & -0.069 & -0.790 \\
\hline & $(0.016)$ & $(0.003)$ & $(0.029)$ & $(0.032)$ & $(0.014)$ & $(0.017)$ \\
\hline \multirow[t]{2}{*}{ Cost Index } & -0.040 & -0.054 & -0.072 & -0.072 & -0.087 & -0.025 \\
\hline & $(0.003)$ & $(0.012)$ & $(0.038)$ & $(0.036)$ & $(0.014)$ & $(0.001)$ \\
\hline \multirow[t]{2}{*}{ Subcontracting } & -0.092 & -0.514 & -0.370 & -0.082 & -0.018 & -0.103 \\
\hline & $(0.104)$ & $(0.566)$ & $(0.164)$ & $(0.109)$ & $(0.000)$ & $(0.006)$ \\
\hline
\end{tabular}

Table 2: Quantile regression results for the sample of plans. Pooled Quantile Regression refers to classical quantile regression applied to pooled data, Panel Quantile Regression denotes Koenker (2004) estimator and Censored Quantile Regression refers to Peng and Huang (2008) estimator. Moreover, OLS denotes Ordinary Least Squares, FE denotes classical fixed effects estimator, and CLAD is the Censored Least Absolute Deviation estimator. The standard errors are obtained after 1000 panel bootstrap repetitions. 
do not have information on whether or not the plant or firm participated in an auction before the window of observation; (ii) the dependent variable is likely to be right-censored for entrants and incumbents; (iii) following our framework in Section 2, the variables size and subcontracting are likely to be endogenous because duration in the market affects size and subcontracting experience of the firm and size or subcontracting are likely to affect duration; (iv) the independent variables are likely to be correlated with firm latent heterogeneity. None of the methods employed in Table 2 jointly address these potential issues. It is immediately apparent that these estimation issues are present in the results associated with size and subcontracting. In the censored regressions, subcontracting, if anything, has a negative effect on duration in the market. We also find that size has no effect on survival which contradicts the existing literature. As we see below, these findings change dramatically when we address the estimation challenges.

We therefore turn to the estimation of a panel duration model with double censored data and endogenous covariates. We estimate $T_{i j}=\exp \left\{\mathbf{s}_{i j}^{\prime} \gamma+\mathbf{x}_{i j}^{\prime} \beta+\alpha_{j}+u_{i j}\right\}$, where $T_{i j}$ denotes the duration in the market in months of plant $i$ associated with firm $j$. Note that $T_{i j}$ is latent and we use the observed duration $Y_{i j}$. The variable $L_{i j}$ is equal to zero for entrants and it is equal to the age of the initial establishment for incumbents. Left censoring occurs for incumbents because we do not observe entry of a branch before 1999 . The variable $\alpha_{j}$ captures effects that are common to establishments within firms. ${ }^{15}$ In this model, it seems natural to consider that the size of an establishment $s_{1, i j}$, measured by the logarithm of average employment, and subcontracting $s_{2, i j}$, measured by the average number of subcontractors in active projects, are endogenous.

To address the potential endogeneity of these variables, we generate a control variable using least squares residuals. Specifically, we obtain $\hat{v}_{k, i j}=\Phi^{-1}\left(s_{k, i j}-\mathbf{R}_{k, i j}^{\prime} \hat{\pi}\right)$ where $\mathbf{R}_{k, i j}=$ $\left(\mathbf{w}_{k, i j}, \mathbf{x}_{i j}^{\prime}, \mathbf{z}_{i}^{\prime}\right)^{\prime}, \mathbf{x}_{i j}$ is a vector of exogenous variables that includes an indicator variable for whether the establishment is an entrant, a composite variable that cover unit costs of

\footnotetext{
${ }^{15}$ Consistent estimation of the quantile function corresponding to equation (2.9) requires to incorporate firm specific controls for productivity that enhance the profit from procurement contracting. These effects include firm specific information and procurement experience that can be shared within a firm that is likely to affect success of establishments in the market. Notice however that the panel is unbalanced as there is a large number of single-establishment firms (Table 1). To avoid issues associated with singular design matrices, we estimate a model with an overall intercept and individual effects for firms who might share information and procurement experience (i.e., firms with more than one establishment). See Appendix A for an investigation of the performance of the estimator when the panel is unbalanced.
} 
different tasks, capacity utilization and backlog variables, $\mathbf{z}_{i}$ is a vector of indicator variables for the individual effects, $k \in\{0,1\}$ and $\Phi(\cdot)$ is the Normal cumulative distribution function. The "excluded" exogenous variables $\mathbf{w}_{i j}$ includes the annual change in the number of single family units approved by building permits prior to the firm's year of birth and the number of plan holders in active projects. The number of single family units by building permits before a plant enters the market should be naturally correlated with the number of subcontractors. On the other hand, pre-determined changes in home renovations including electrical work and plumbing should be independent of project costs of a plant that participates in the procurement auctions years later. Moreover, the number of plan holders is uncorrelated with latent time-varying drivers of survival in the market as the number of plan holders in an auction identifies the maximum number of bidders that expressed interest in the project and may submit bids. With respect to the correlation between number of plan holders and size, we argue that the number of plans held by a firm determines the likelihood of winning and eventually the number of employees needed to complete the project. The number of plan holders has been used in the empirical auction literature (De Silva, Dunne, Kankanamge and Kosmopoulou 2008). The other independent variables are considered to be exogenous variables conditioning on $\alpha_{j}$. As in Section 2.2, the estimator is obtained in a second step using the control variable $\hat{\mathbf{v}}_{i j}{ }^{16}$

The results are presented in Figure 4. The figure presents estimates of the main covariate effects as a function of the quantile $\tau$ of the conditional distribution of duration. In each graph, the continuous line shows the point estimates and the shaded region represents a 90\% confidence interval for the point estimates. For instance, the first graph on the top row shows estimates of the effect of size on duration. The estimate is positive and significant at the 0.25 quantile and it tends to decrease as we go across quantiles. The advantage of the figure is that it allows us to carefully examine the effect of the independent variables of interest at any quantile. As expected, the size of the plant is likely to affect the duration in the market which was not implied by the results presented in Table 2 . The main results suggest that duration in construction business is affected by the procurement auctions through subcontracting and changes in the input prices of active projects. (The sole exception is the effect of subcontracting at the upper tail of the conditional distribution). Having a net-

\footnotetext{
${ }^{16}$ We examine the robustness of our results to alternative excluded exogenous variables in Appendix C.
} 

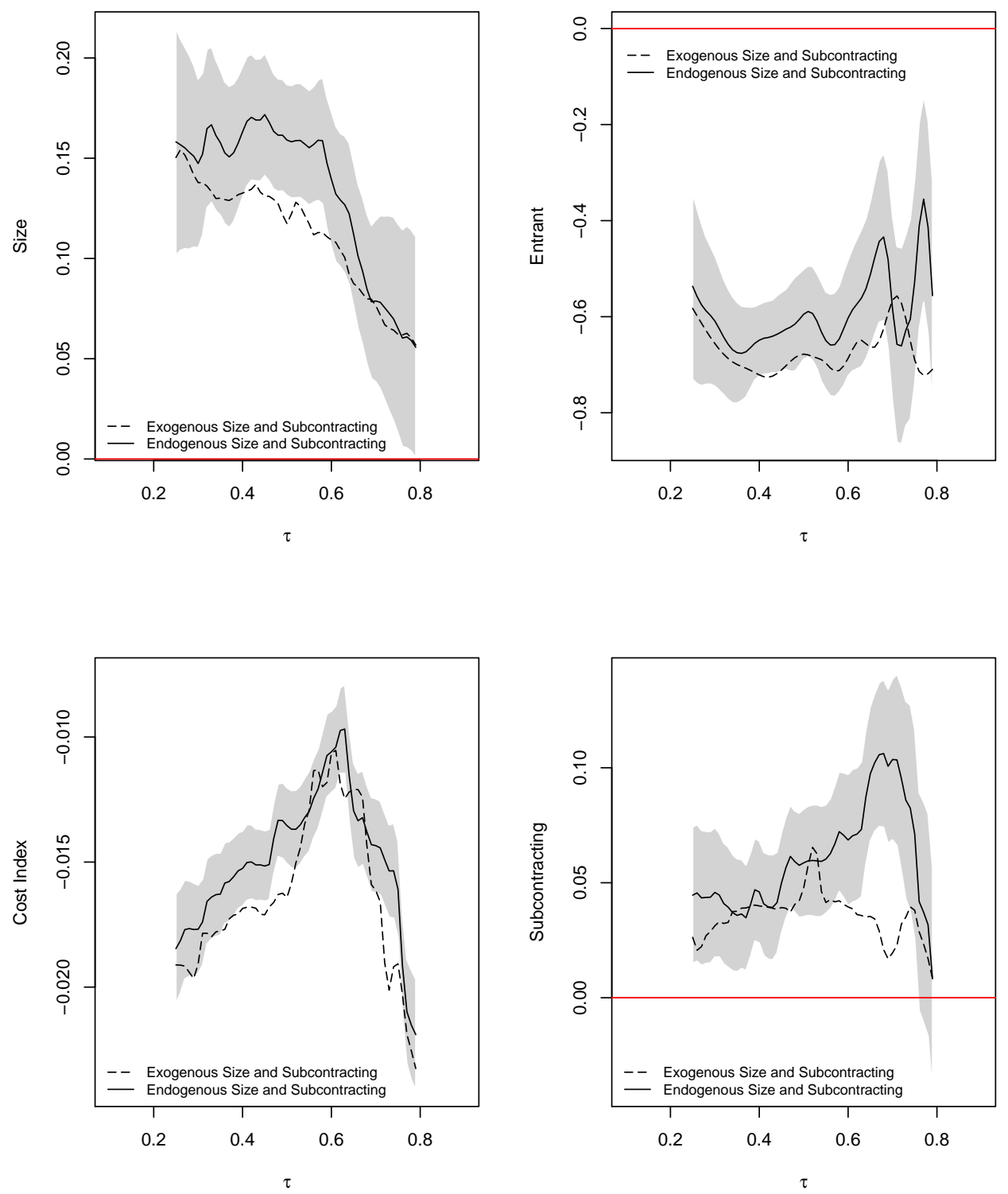

Figure 4: Quantile regression results for the main covariate effects on duration. The quantiles of the conditional duration distribution are denoted by $\tau$. The continuous dotted lines show estimates obtained from the PQRC estimator proposed in this paper. The shaded regions represent a 90 percent point-wise confidence interval. 

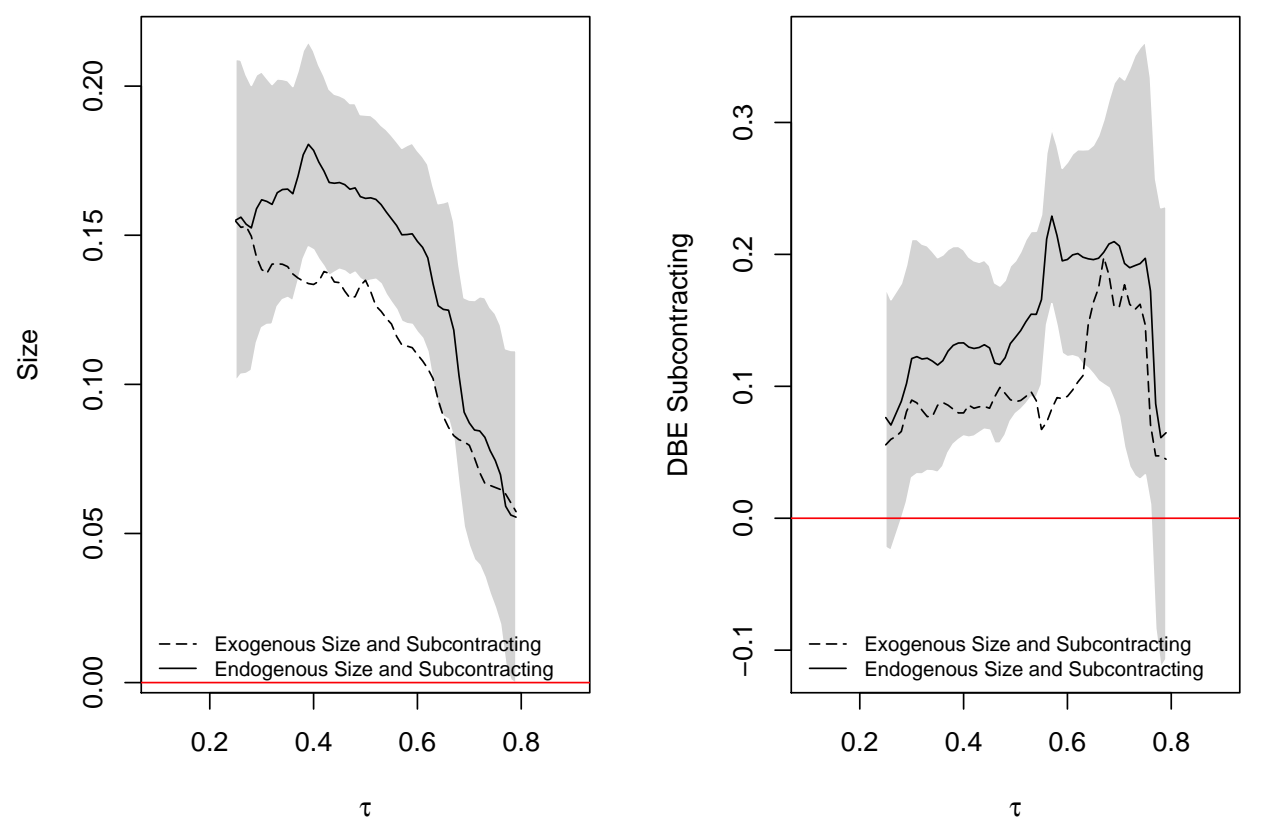

Figure 5: Quantile regression results for the effect of size and subcontracting on duration. The quantiles of the conditional duration distribution are denoted by $\tau$. The continuous dotted lines show estimates obtained from the PQRC estimator proposed in this paper. The shaded regions represent a 90 percent point-wise confidence interval. 
work of subcontractors that can share information and project risks increases the duration in business.

We implemented Wald-type tests to evaluate whether the effects of size and subcontracting are different across quantiles. We evaluated whether the effects of interest are significantly different between two quantiles, say $\tau_{1}$ and $\tau_{j}$ for $j \in\{2,3, \ldots M\}$. The results indicate that the effect of size is significantly different between the 0.25 and 0.75 quantiles and the effect of subcontracting is significantly different between the 0.25 and 0.65 quantiles. In the case of subcontracting, the null hypothesis $\gamma_{2}(0.25)=\gamma_{2}(0.65)$ is weakly rejected at $10 \%$. Moreover, to examine the effect of ignoring endogeneity in panel duration models, we offer results obtained by the same procedure while assuming that size and subcontracting are exogenous. As explained in Section 2, the estimation procedure is similar but we do not augment the design matrix with the control variables. As in the case of endogenous variables, the (dashed) line shows the point estimates. ${ }^{17}$ The new results suggest that the effect of size is underestimated at the low conditional quantiles of the duration distribution if we assume that size and subcontracting are exogenous. Moreover, the effect of subcontracting is attenuated towards zero. These results might be interpreted within the framework developed in Section 2.1, which implies that there are latent components of cost not adequately controlled for by other covariates in the $\tau$-th conditional quantile model. Because higher costs are likely to negatively affect duration, the comparison between point estimates in Figure 4 suggest that firm cost is increasing in size and number of subcontractors, as one might have expected. ${ }^{18}$

Figure 5 shows results from estimating the model as in Figure 4 with the exception that subcontracting $s_{2, i j}$ is now measured by the average number of Disadvantaged Business Enterprises (DBEs) in active projects. To address the potential endogeneity of the DBE subcontracting variable, we generate the control variables using least squares residuals and

\footnotetext{
${ }^{17}$ Because they to not represent the main findings and to simplify the visual analysis of the results, we do not provide a $90 \%$ point-wise confidence interval in Figure 4 for the case of exogenous size and subcontracting. Size remain to be significant at $\tau \leq 0.7$ but subcontracting is in general insignificant at $10 \%$ (the sole exceptions are the estimates around the median conditional quantile).

${ }^{18}$ The effect of higher costs on size is not immediately apparent and the sign might not be determined. On the one hand, it is natural to expect that higher costs negatively affect the average size of an establishment. On the other hand, higher costs over time are likely to be driven by complex and large projects undertaken by an establishment. At the same time, the number of employees is likely to increase if the firm wins projects. Therefore, higher procurement costs can also correlate positively with size. The evidence suggest that this second channel is more important, although the differences between estimates in Figure 4 are, in general, not significantly different across quantiles.
} 

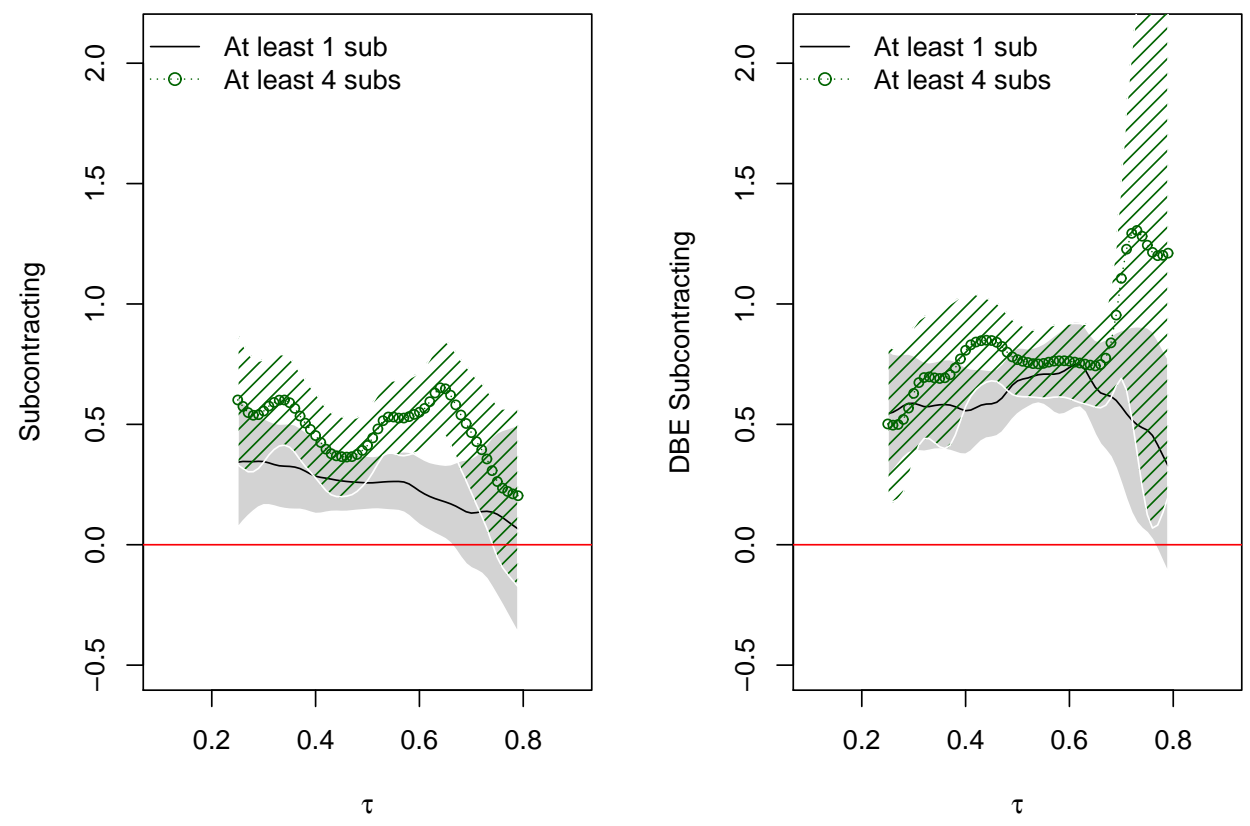

Figure 6: Quantile regression results for the effect of the number of subcontractors on duration. The shaded regions represent a 90 percent point-wise confidence interval.

the same instruments used to obtain the results shown in Figure 4. The excluded exogenous variables are the change in the number of single family units approved by building permits prior to the firm's year of birth and the number of plan holders in active projects, which not likely to affect duration conditional on firm heterogeneity. ${ }^{19}$

The findings suggest that when contractors employ as subcontractors minority and women owned businesses, known as DBEs, the effects on survival are more pronounced. Additionally, we find that the effect of DBE subcontracting appears to be larger among firms using 4 or more DBE subcontractors in the period of analysis (Figure 6). Contrary to what one would expect, as DBE subcontracting is often linked to government imposed goals that can lead to inefficiencies (see Marion 2009), Figure 5 suggests that if a relatively young firm has utilized DBE subcontractors it is likely to survive longer in business. Although the shape of

\footnotetext{
${ }^{19}$ As a reviewer suggested, an alternative identification strategy for the effect of DBE subcontracting can be based upon the timing of implementation of programs across states.
} 
the subcontracting effects is similar to the results shown in Figure 4, the estimated effects are roughly two times larger at several quantiles including $\tau=0.25{ }^{20}$ Even though there is a large number of minority-owned construction firms in Texas and the program that encouraged the formation and success of DBEs has increased the supply of those firms without increasing the cost to the state (see De Silva, Dunne, Kosmopoulou and Lamarche 2012), the results go a step further to suggest that DBE subcontracting may have positive external effects on competitors.

Subcontracting allows establishments to smooth out constraints in contracting and therefore benefits an establishment if other firms have extensive experience in specific tasks. DBE subcontractors will likely fit this profile because the program in Texas appears to have encouraged the formation of minority and women owned businesses who often undertake subcontracting work either within or outside the federally imposed DBE subcontracting goals. $^{21}$

There is a long debate on the value of policies targeting small or disadvantaged businesses with evidence provided on costs and benefits (see Marion (2009, 2015) and De Silva, Dunne, Kosmopoulou, and Lamarche (2012) for some related findings). Nakabayashi (2013) considers in a counterfactual estimation the impact on firm exit, of eliminating incentives targeting small businesses in Japan. He finds that elimination of such programs would induce exit of $40 \%$ of existing small business firms. That reduction in competition would increase the cost of procurement.

\subsection{Empirical Evidence from a Sample of Entrants}

This section considers a series of robustness checks on the specifications and assumptions behind the models estimated in the previous section. The results are shown in Table 3.

\footnotetext{
${ }^{20}$ We accommodated existing Wald-type tests to evaluate whether the effects of size and subcontracting in Figure 5 are significantly different across quantiles. The results indicated that the effect of size is not significantly different at 5 percent significance level across quantiles with the exception when we tested the null hypothesis $\gamma_{1}(0.25)=\gamma_{1}(0.75)$. The test had a $p$-value equal to 0.032. Moreover, the effect of DBE subcontracting does not significantly change across quantiles. However, as it can be seen in Figure 5 , the effect of DBE subcontracting is statistically significantly different from zero (the exceptions are the lower and upper quantiles of the conditional duration distribution).

${ }^{21}$ Information from the Census Bureau's 2002 Survey of Business Owners indicates that there is a relatively large number of minority-owned construction firms in Texas in comparison to other states. This is associated, in part, with the large minority population residing in the state.
} 


\begin{tabular}{lccccc}
\hline \multirow{2}{*}{ Sample } & \multicolumn{5}{c}{ Effect of subcontracting in active projects } \\
\cline { 2 - 6 } & 0.1 & 0.25 & 0.5 & 0.75 & 0.9 \\
\hline Entrants & 0.715 & 0.696 & 0.290 & 0.148 & 0.104 \\
& $(0.314)$ & $(0.236)$ & $(0.171)$ & $(0.062)$ & $(0.039)$ \\
\hline Entrant firms (cohorts 2000 and 2001) & 0.283 & 0.535 & 0.529 & 0.167 & 0.125 \\
& $(0.354)$ & $(0.431)$ & $(0.280)$ & $(0.136)$ & $(0.036)$ \\
\hline Contractors (cohorts 2000 and 2001) & 0.974 & 0.929 & 0.626 & 0.172 & 0.137 \\
& $(0.449)$ & $(0.340)$ & $(0.298)$ & $(0.189)$ & $(0.061)$ \\
\hline Entrants firms with outside options & 0.584 & 0.462 & 0.265 & 0.161 & 0.109 \\
& $(0.376)$ & $(0.277)$ & $(0.233)$ & $(0.088)$ & $(0.055)$ \\
\hline Entrants firms without outside options & 0.856 & 0.806 & 0.223 & 0.071 & 0.029 \\
& $(0.321)$ & $(0.283)$ & $(0.193)$ & $(0.107)$ & $(0.069)$ \\
\hline Control variables & Yes & Yes & Yes & Yes & Yes \\
Project specific controls & Yes & Yes & Yes & Yes & Yes \\
Firm Effects & Yes & Yes & Yes & Yes & Yes \\
Control function & Yes & Yes & Yes & Yes & Yes \\
\hline
\end{tabular}

Table 3: Panel duration quantile regression results for the logarithm of survival times. Control variables include size, unemployment and cost index of active projects. Project specific controls include the value of the engineer's cost estimate of the project, the total number of bid items in a project, and indicators for projects grouped into asphalt and bridge categories. The control variable function is based on the number of plan holders in active projects, a lagged value of the number of plan holders, a lagged value of logarithm of employment and lagged values of number of firms in single-family and multifamily housing construction. The standard errors are obtained after 1000 panel bootstrap repetitions.

These results are obtained by restricting the sample of firms to include entrants and defining the dependent variable as $T_{i j}$, where $i$ denotes establishments and $j$ indicates age of the establishment in months. A survival model for $T_{i j}$ can be estimated by the proposed approach, provided that the data is organized following a $m$-line record. ${ }^{22}$ In what follows, we discuss the importance of subcontracting among entrants, business cycle effects and the effect of work outside the procurement auctions on firms' duration in business.

\footnotetext{
${ }^{22}$ It refers to the idea that we can split the observed duration data into segments. During $m-1$ periods, the covariates are time-varying and the censoring variable is equal to 1 because the firm is observed. The last segment includes the final observed duration, covariates and a censoring variable equal to 0 . The interested reader can find additional details on page 598 of Cameron and Trivedi (2005).
} 


\subsubsection{Subcontracting and Survival of Entrants}

Following the framework adopted in section 2, as before, we assume that the size of a firm, measured by the logarithm of total employment, and subcontracting are endogenous variables. However the difference with respect to our previous results is that we concentrate on the effects of subcontracting using a sample of entrants. To obtain the control variable function, we include in $\mathbf{w}$ the number of plan holders in active projects, a lagged value of the number of plan holders, a lagged value of the logarithm of employment and lagged values of number of firms in single-family and multi-family housing construction. In addition to the controls used in the previous section, the model includes project specific covariates and individual effects, which could be associated to firm specific productivity or level of involvement in complementary activity that can affect business profit. Notice that these latent factors may be expected to be correlated with size and subcontracting. Project specific controls include the value of the engineer's cost estimate of the project, the total number of project components in a project, and indicators for projects grouped into the asphalt and bridge categories. The first row of the table shows that the effect of subcontracting in active projects is positive and significant at the lowest quantiles, suggesting that subcontracting prolongs (conditional) duration in business. Subcontracting allows one to share valuable information to reduce uncertainty and risks, and seems to be more important at early stages of a firm's life.

\subsubsection{Business cycle effects}

Price fluctuations related to the business cycle may affect entry in the procurement auctions. One would think that high oil prices in the 2000's may have led to entry of relatively highlyefficient firms. Or alternatively, funds on infrastructure projects to stimulate the economy simultaneously affected the type of firms buying plans and bidding. ${ }^{23}$ In order to isolate the effect of business cycle movements on duration in business, we restrict our sample to include (a) entrants who bought a plan in 2000 and 2001 but did not necessarily win a contract, and

\footnotetext{
${ }^{23} \mathrm{~A}$ significant portion of the funds on infrastructure projects in US was devoted to restore and rebuild bridges. The American Association of State Highway and Transportation Official (AASHTO) 2008 report, entitled "Bridging the Gap: Restoring and Rebuilding the Nation's Bridges", stated that of the 600,000 U.S. bridges, nearly 152,000 need significant repair. "Almost one in four bridges, while safe to travel, is either structurally deficient, or in need of repair."
} 
(b) firms who did road construction (surfacing/resurfacing) work. Considering these samples, we re-estimate the models and present the results in Table 3. The evidence is consistent with the theory and the previous results. It continues to suggest that subcontracting affects survival of contractors in the road construction industry.

\subsubsection{Limited business opportunities outside road construction}

The potential losses associated with uncertainty and project risks may be mitigated by the existence of alternative business options. In light of the framework in Section 2 and theoretical and experimental evidence in Kirchkamp, Poen, and Reiß (2009), it is of interest to revisit our findings and distinguish among firms by their dependence on road construction procurement, and consequently, their access to outside business options. ${ }^{24}$

After discussions with state highway and civil engineers and based on the original NAICS classification and additional information obtained from descriptions of their activities, we created two relevant groups, and accordingly, in Table 3, we divided the sample of contractors into two sub-samples: firms with outside options (e.g., landscaping, plumbing, heating, etc.) and firms with few or no outside options (e.g., bridge construction, highway and street construction, etc.). ${ }^{25,26}$ Notice that the first group includes firms whose survival in the industry does not crucially depend upon the outcome of the procurement auction process for road construction, and the second group include firms whose survival mainly depends upon these contracts.

The evidence in Table 3 for firms whose survival does not depend on the procured government projects suggests a positive but insignificant effect of subcontracting at the lowest quantiles of the survival distribution. While the estimated effect of subcontracting is insignificant at the 0.1 quantile among firms with outside options, it is positive and significant for

\footnotetext{
${ }^{24}$ Kirchkamp, Poen, and Reiß (2009) studied the effect of the presence of outside options in bidding. They showed that, bidders respond to outside options by softening bidding aggressiveness.

${ }^{25}$ The North American industry classification system (NAICS) allows us to distinguish among commercial and institutional building contractors, electrical contractors, highway, street and bridge contractors, firms offering landscaping services, new single-family housing contractors, and other building finishing contractors.

${ }^{26}$ Although it is in principle plausible to classify firms by activities using the NAICS code, its level of aggregation is an obvious limitation. Consider for instance, firms that were reported to provide services in the highway, street, and bridge construction industry. This category includes a contractor offering services in bridge construction as well as a contractor offering plumbing services. While firms in bridge construction may have limited options outside procurement contracting, firms offering plumbing services have other opportunities in business.
} 
firms with few or no outside options. We interpret this result as suggesting that subcontracting can have a more advantageous effect on survival for firms with few or no outside options (e.g., bridge contractors). It should be noted however that these effects do not appear to be significantly different at standard levels of significance.

\section{Conclusion}

This paper investigates how subcontracting parts of contracted work affects firm's survival. We apply a panel duration quantile regression approach to a sample of data from firms in road construction. This industry displays market concentration featuring only a small number of firms, thus limiting the competitiveness of market outcomes. We construct a unique data set of entrants and propose a semi-parametric approach that simultaneously addresses issues associated with firm's latent heterogeneity, endogenous time-varying covariates and double censored data. The approach offered in this paper appears to perform well relative to other approaches being studied in the literature of quantile regression for duration data. Our quantile regression approach allows us to investigate survival beyond the mean effect, which is important in the context of understanding the determinants of young firms' duration in business and the effect of DBE policies on firm survival.

Our results indicate that employing subcontractors can have a positive effect on duration in business, in particular at early stages of a firm's life. Those effects are more distinct for firms with limited business options outside road construction and those who employ DBE firms as subcontractors. The results also suggest that programs similar to Mentor-protégé in Texas and Connect2DOT in Colorado, which provide firms the opportunity to create a network of subcontractors, can enhance their survival.

\section{References}

Baldwin, J. R., And P. K. Gorecki (1991): "Firm Entry and Exit in the Canadian Manufacturing Sector, 1970-1982," The Canadian Journal of Economics, 24, 300-323.

Blundell, R., And J. L. Powell (2007): "Censored Regression Quantiles with Endogenous Regressors," Journal of Econometrics, 141, 65-83. 
Branzoli, N., and F. Decarolis (2015): "Entry and Subcontracting in Public Procurement Auctions," Management Science, forthcoming.

Cameron, A. C., and P. K. Trivedi (2005): Microeconometrics: Methods and Applications. Cambridge.

Chen, S., And S. Khan (2001): "Semiparametric Estimation of a Partially Linear Censored Regression Model," Econometric Theory, 17, 567-590.

Chernozhukov, V., I. Fernndez-Val, and A. E. Kowalski (2015): "Quantile regression with censoring and endogeneity," Journal of Econometrics, 186(1), 201 - 221.

De Silva, D. G., T. Dunne, A. Kankanamge, and G. Kosmopoulou (2008): "The Impact of Public Information on Bidding in Highway Procurement Auctions," European Economic Review, 23(3-4), 150-181.

De Silva, D. G., T. Dunne, G. Kosmopoulou, and C. Lamarche (2012): "Disadvantaged Business Enterprises Goals in Government Procurement Contracting: an Analysis of Bidding Behavior and Costs," International Journal of Industrial Organization, 30, $377-388$.

De Silva, D. G., T. D. Jeitschko, and G. Kosmopoulou (2005): "Stochastic Synergies in Sequential Auctions," International Journal of Industrial Organization, 23, 183-201.

De Silva, D. G., G. Kosmopoulou, and C. Lamarche (2009): "The effect of information on the bidding and survival of entrants in procurement auctions," Journal of Public Economics, 93, $56-72$.

Dunne, T., J. B. Jensen, And M. Roberts (eds.) (2009): Producer Dynamics. New Evidence from Micro Data, vol. 68 of NBER Studies in Income and Wealth. The University of Chicago.

Dunne, T., M. J. Roberts, and L. Samuelson (1988): "Patterns of Firm Entry and Exit in U.S. Manufacturing Industries," Rand Journal of Economics, 19(4), 495-515.

Firpo, S., N. M. Fortin, And T. Lemieux (2009): "Unconditional Quantile Regressions," Econometrica, 77(3), 953-973. 
Fitzenberger, B., and R. Wilke (2006): "Using Quantile Regression for Duration Analysis," Allgemeines Statistisches Archive, 90(1), 105-120.

FrÖLICH, M., AND B. Melly (2013): "Unconditional Quantile Treatment Effects Under Endogeneity," Journal of Business ES Economic Statistics, 31(3), 346-357.

Galvao, A. F., C. Lamarche, and L. R. Lima (2013): "Estimation of Censored Quantile Regression for Panel Data With Fixed Effects," Journal of the American Statistical Association, 108(503), 1075-1089.

Gil, R., And J. MARion (2013): "Self-Enforcing Agreements and Relational Contracting: Evidence from California Highway Procurement," Journal of Law, Economics and Organization, 29(2), $239-277$.

Harding, M., and C. Lamarche (2012): "Quantile Regression Estimation of Panel Duration Models with Censored Data," in Essays in Honor of Jerry Hausman (Advances in Econometrics, Volume 29), chap. 15, pp. 237-267.

Helfat, C., and M. B. Lieberman (2002): "The birth of capabilities: market entry and the importance of pre-history," Industrial and Corporate Change, 11(4), 726-760.

Honoré, B. E., And A. de Paula (2010): "Interdependent Durations," Review of Economic Studies, 77(3), 1138 - 1163.

Horowitz, J. L., And S. LeE (2004): "Semiparametric Estimation of a Panel Data Proportional Hazard Model with Fixed Effects," Journal of Econometrics, 119, 155-198.

Jeitschko, T. D., And E. Wolfstetter (2002): "Scale Economics and the Dynamics of Recurring Auctions," Economic Inquiry, 23, 403-414.

Jeziorski, P., And E. Krasnokutskaya (2016): "Dynamic Auction Environment with Subcontracting," mimeo, Haas School of Business.

Ji, S., L. Peng, Y. Cheng, and H. Lai (2012): "Quantile Regression for Doubly Censored Data," Biometrics, 68(1), 101-112.

Jin, Z., Z. YING, AND L. J. WEI (2001): "A simple resampling method by perturbing the minimand," Biometrika, 88(2), 381-390. 
Khan, S., And E. Tamer (2007): "Partial Rank Estimation of Transformation Models with General Forms of Censoring," Journal of Econometrics, 136, 251-280.

(2009): "Inference on Endogenously Censored Regression Models Using Conditional Moment Inequalities," Journal of Econometrics, 152, 104-119.

KIM, M.-O., AND Y. YAng (2011): "Semiparametric Approach to a Random Effects Quantile Regression Model," Journal of the American Statistical Association, 106, 1405-1417.

Kirchkamp, O., E. Poen, and P. Reiss (2009): "Outside Options: Another reason to choose the first price auction," European Economic Review, 53, 153-169.

Koenker, R. (2004): "Quantile Regression for Longitudinal Data," Journal of Multivariate Analysis, 91, 74-89.

Lancaster, T. (1990): The Econometric Analysis of Transition Data. Cambridge University Press.

LEe, S. (2008): "Estimating Panel Data Duration Models with Censored Data," Econometric Theory, 24.

Leufkens, K., R. Peeters, and D. Vermeulen (2010): "Sequential auctions with synergies: The paradox of positive synergies," Economics Letters, 109(3), 139 - 141.

Lin, G., X. He, And S. Portnoy (2012): "Quantile regression with doubly censored data," Computational Statistics $\&$ Data Analysis, 56(4), 797 - 812.

Ma, S., And M. R. Kosorok (2005): "Robust semiparametric M-estimation and the weighted bootstrap," Journal of Multivariate Analysis, 96(1), 190 - 217.

Marion, J. (2009): "How Costly is Affirmative Action? Government Contracting and California's Proposition 209," Review of Economics and Statistics, 91, 503-522.

MARION, J. (2015): "Sourcing from the Enemy: horizontal Subcontracting in Highway Procurement," Journal of Industrial Economics, 63(1), 100 - 128.

Miller, D. P. (2014): "Subcontracting and Competitive Bidding on Incomplete Procurement Contracts," Rand Journal of Economics, 45(4), 705746. 
Moretti, L., and P. Valbonesi (2015): “Firms' Qualifications and Subcontracting in Public Procurement: An Empirical Investigation," Journal of Law, Economics and Organization, 31(3), 568-598.

NAKABAYASHI, J. (2013): "Small business set-asides in procurement auctions: An empirical analysis," Journal of Public Economics, 100, 28-44.

Peng, L., And Y. Huang (2008): "Survival Analysis With Quantile Regression Models," Journal of the American Statistical Association, 103, 637-649.

Portnoy, S. (2003): "Censored Regression Quantiles," Journal of The American Statistical Association, 98, 1001-1010.

Powell, J. L. (1984): "Least Absolute Deviations Estimation of the Censored Regression Model," Journal of Econometrics, 25, 303-325.

(1986): "Censored Regression Quantiles," Journal of Econometrics, 32, 143-155.

SEIM, K. (2001): "Spatial Differentiation and Firm Entry: The Video Retail Industry," Yale University, New Haven, CT.

\section{A Appendix A: Simulation Study}

In this section, we briefly report results from several simulation experiments designed to evaluate the performance of the estimator defined in equation (2.13). We generate the dependent variable considering a design similar to Harding and Lamarche (2012):

$$
\begin{aligned}
T_{i j} & =5+s_{i j}+x_{i j}+\alpha_{i}+u_{i j}, \\
s_{i j} & =w_{i j}+v_{i j}, \\
\alpha_{i} & =\pi \bar{s}_{i}+\varepsilon_{i} .
\end{aligned}
$$

where the instrument is $w_{i j}=0.25 \eta_{i}+e_{i j}$ and the observed independent variable is generated as $Y_{i j}=\max \left\{L_{i j}, \min \left\{T_{i j}, U_{i j}\right\}\right\}$. As before $L_{i j}$ and $U_{i j}$ indicates censoring times and $\bar{s}_{i}=$ $m^{-1} \sum_{j=1} s_{i j}$ is the individual specific sample mean of the endogenous variable $s_{i j}$. The error terms in equations (A.1) and (A.2) are $\left(u_{i j}, v_{i j}\right) \sim N(\mathbf{0}, \boldsymbol{\Omega})$, where $\Omega_{11}=\Omega_{22}=1$. The random variable $\varepsilon_{i}$ is normally distributed with mean zero and variance 0.5 , and the variables 
$\left(e_{i j}, x_{i j}, \eta_{i}\right)$ are Gaussian independent random variables. Throughout the simulations, we adopt a fixed censoring scheme by setting $L_{i j}=1$ and $U_{i j}=7.5$. We consider four basic variations of the model:

Design 1: The endogenous variable $s_{i j}$ is not correlated with $\alpha_{i}$, and the variables $\left(u_{i j}, v_{i j}\right)$ in equations (A.1) and (A.2) are independent Gaussian variables. We assume $\pi=$ $\Omega_{21}=\Omega_{12}=0$.

Design 2: We continue to assume that $s_{i j}$ is not correlated with $\alpha_{i}$, but now $\left(u_{i j}, v_{i j}\right)$ are not independent random variables. We consider $\Omega_{12}=\Omega_{21}=-0.5$.

Design 3: We consider the case that $\left(u_{i j}, v_{i j}\right)$ are independent Gaussian variables and $s_{i j}$ is correlated with $\alpha_{i}$ by assuming that $\pi=-0.5$ in equation (A.3).

Design 4: The variables $\left(u_{i j}, v_{i j}\right)$ are not independent random variables and $s_{i j}$ is correlated with $\alpha_{i}$. We assume $\pi=\Omega_{12}=\Omega_{21}=-0.5$.

Design 5: The data is generated as in Design 4. However, we generate data from an unbalanced panel data model where $70 \%$ of the cross-sectional units are observed once $\left(m_{i}=1\right)$ and the other $30 \%$ are observed multiple times.

Table A.1 shows results from several quantile regression estimators: (i) a naive quantile regression approach that uses the censored variable $Y(\mathrm{QR})$, (ii) a fixed effects approach (FEQR) that while addressing issues of dependence between $\alpha_{i}$ and $x_{i j}$ ignores censoring, (iii) an instrumental variable method (IVQR), (iv) the survival approach for a censored quantile regression model (PH) proposed by Peng and Huang (2008), and (v) the quantile regression estimator proposed in this paper (PQDC). As in Section 2.2, the estimator is obtained in two steps. In the first step, we generate the control variable using the least squares residuals obtained from a parametric regression of the endogenous variable $s_{i j}$ on the instrument $w_{i j}$. The table presents the bias of the estimators and their root mean square error (RMSE) for the slope $\beta_{1}=1$ in equation (A.1) at two quantiles $\tau=\{0.25,0.50\}$, considering $n=50$ and $m=15$. The average number of time series observations $\bar{m}=n^{-1} \sum_{i=1}^{n} m_{i}=5$. Tables A.2 and A.3 show additional results for $n=20$ and $m=50$.

It is important to note that the three procedures (QR, FEQR, IVQR) being compared are not designed to address issues with censored data and QR and IVQR are cross-sectional 
methods. Moreover, one procedure (PH) addresses top or bottom censored data but not both at the same time and ignores the potential correlation between $\left(\alpha_{i}, u_{i j}\right)$ and $s_{i j}$. However, the procedures being compared with the proposed approach are the feasible alternatives for practitioners planning to study the survival of firms in the road construction industry.

We begin comparing the different estimators in the absence of endogeneity or correlated individual effects (upper panels, Table A.1). Note, however, that the dependent variable $Y_{i j}$ is censored at the left and right tails. We find that our estimator offers a substantial improvement relative to the competing methods including the Peng-Huang estimator. As we introduce endogeneity in Designs 2 to 4, by allowing for correlated individual effects and/or correlation between the independent variable of interest and the error term in equation (A.1), the performance of our estimator continues to be satisfactory. Under Design 4, the performance of the PH estimator seems satisfactory as well in the sense that QR, FEQR and IVQR have substantially larger bias than the $\mathrm{PH}$ estimator at the 0.25 quantile. It should be noted however that the bias of the $\mathrm{PH}$ estimator is larger than that of the PQDC estimator. In terms of RMSE, the PQDC estimator offers the best small sample performance in these simulations, although the PH estimator shows smaller variance than the PQDC estimator. This is to be expected since the PQDC estimator includes a control variable, and, more importantly, $n$ individual effects.

Lastly, Table A.1 shows results obtained using an unbalanced panel. Design 5 is motivated by the panel dataset used in the empirical application, which includes $72 \%$ of firms that are single establishments. The average number of establishments is 3 and the maximum number is 15. As expected in the case of unbalanced panels, the performance of the estimator deteriorates relative to the case with $\bar{m}=m=15$ or $\bar{m}=m=50$. However, the estimator continues to exhibit low bias and it offers the best performance in the class of estimators for duration models in quantile regression. Note that the bias of the proposed PQDC estimator ranges between $2.3 \%$ and $8.5 \%$, while the bias of the other competing methods range between $20 \%$ and $45 \%$.

Overall, the simulations suggest that our proposed panel quantile estimator performs well under fixed censoring and is preferred over existing methods when there is interest to address issues of endogeneity and correlated individual effects. 


\begin{tabular}{|c|c|c|c|c|c|c|c|c|c|c|c|}
\hline & \multirow[t]{2}{*}{$\tau$} & \multirow[t]{2}{*}{$n$} & \multirow[t]{2}{*}{$m$} & \multirow[t]{2}{*}{$\bar{m}$} & \multicolumn{2}{|c|}{$s_{i j} \not L:$} & \multicolumn{5}{|c|}{ Quantile Estimators } \\
\hline & & & & & $u_{i j}$ & $\alpha_{i}$ & QR & FEQR & IVQR & $\mathrm{PH}$ & PQDC \\
\hline & \multicolumn{11}{|c|}{ Design 1} \\
\hline Bias & .25 & 50 & 15 & 15 & No & No & -0.117 & -0.124 & -0.121 & -0.101 & -0.005 \\
\hline RMSE & 25 & 50 & 15 & 15 & No & No & 0.122 & 0.128 & 0.132 & 0.113 & 0.056 \\
\hline Bias & 50 & 50 & 15 & 15 & No & No & -0.112 & -0.119 & -0.111 & -0.091 & -0.004 \\
\hline \multirow[t]{2}{*}{ RMSE } & 50 & 50 & 15 & 15 & No & No & 0.118 & 0.124 & 0.124 & 0.102 & 0.058 \\
\hline & \multicolumn{11}{|c|}{ Design 2} \\
\hline Bias & 25 & 50 & 15 & 15 & Yes & No & -0.292 & $\begin{array}{l}-0.303 \\
\end{array}$ & $\begin{array}{l}-0.082 \\
\end{array}$ & -0.067 & 0.009 \\
\hline $\mathrm{RN}$ & 25 & 50 & 15 & 15 & Yes & No & & 304 & 0.095 & 0.083 & 058 \\
\hline Bias & .50 & 50 & 15 & 15 & Yes & No & -0.290 & -0.308 & -0.075 & -0.287 & 0.006 \\
\hline \multirow[t]{2}{*}{ RMSE } & 50 & 50 & 15 & 15 & Yes & No & 0.292 & 0.309 & 0.092 & 0.290 & 0.047 \\
\hline & \multicolumn{11}{|c|}{ Design 3} \\
\hline Bias & 25 & 50 & 15 & 15 & $\mathrm{No}$ & Yes & -0.174 & -0.121 & -0.202 & -0.095 & -0.004 \\
\hline RMSE & 0.25 & 50 & 15 & 15 & No & Yes & 0.178 & 0.124 & 0.210 & 0.108 & 0.054 \\
\hline Bias & 50 & 50 & 15 & 15 & No & Yes & -0.175 & -0.113 & -0.205 & -0.170 & -0.002 \\
\hline \multirow[t]{2}{*}{ RMSE } & 0.50 & 50 & 15 & 15 & No & Yes & 0.181 & 0.119 & 0.213 & 0.177 & 0.056 \\
\hline & \multicolumn{11}{|c|}{ Design 4} \\
\hline Bias & 25 & 50 & 15 & 15 & Yes & Yes & -0.359 & -0.313 & -0.176 & -0.058 & 0.000 \\
\hline RMSE & 25 & 50 & 15 & 15 & Yes & Yes & 0.361 & 0.314 & 0.186 & 0.075 & 0.051 \\
\hline Bias & 0.50 & 50 & 15 & 15 & Yes & Yes & -0.367 & -0.317 & -0.186 & -0.378 & -0.002 \\
\hline \multirow[t]{2}{*}{ RMSE } & 0.50 & 50 & 15 & 15 & Yes & Yes & 0.369 & 0.318 & 0.195 & 0.381 & 0.054 \\
\hline & \multicolumn{11}{|c|}{ Design 5} \\
\hline 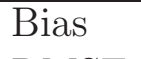 & .25 & 50 & 15 & 5 & Yes & Yes & -0.395 & -0.340 & -0.188 & -0.281 & -0.023 \\
\hline RMSE & 0.25 & 50 & 15 & 5 & Yes & Yes & 0.401 & 0.344 & 0.208 & 0.288 & 0.092 \\
\hline Bias & 0.50 & 50 & 15 & 5 & Yes & Yes & -0.425 & -0.383 & -0.212 & -0.288 & -0.085 \\
\hline RMSE & 0.50 & 50 & 15 & 5 & Yes & Yes & 0.429 & 0.386 & 0.228 & 0.292 & 0.119 \\
\hline
\end{tabular}

Table A.1: Simulation results under fixed left- and right-censoring (double censoring). The table shows the bias and root mean square error (RMSE) of different estimators. 


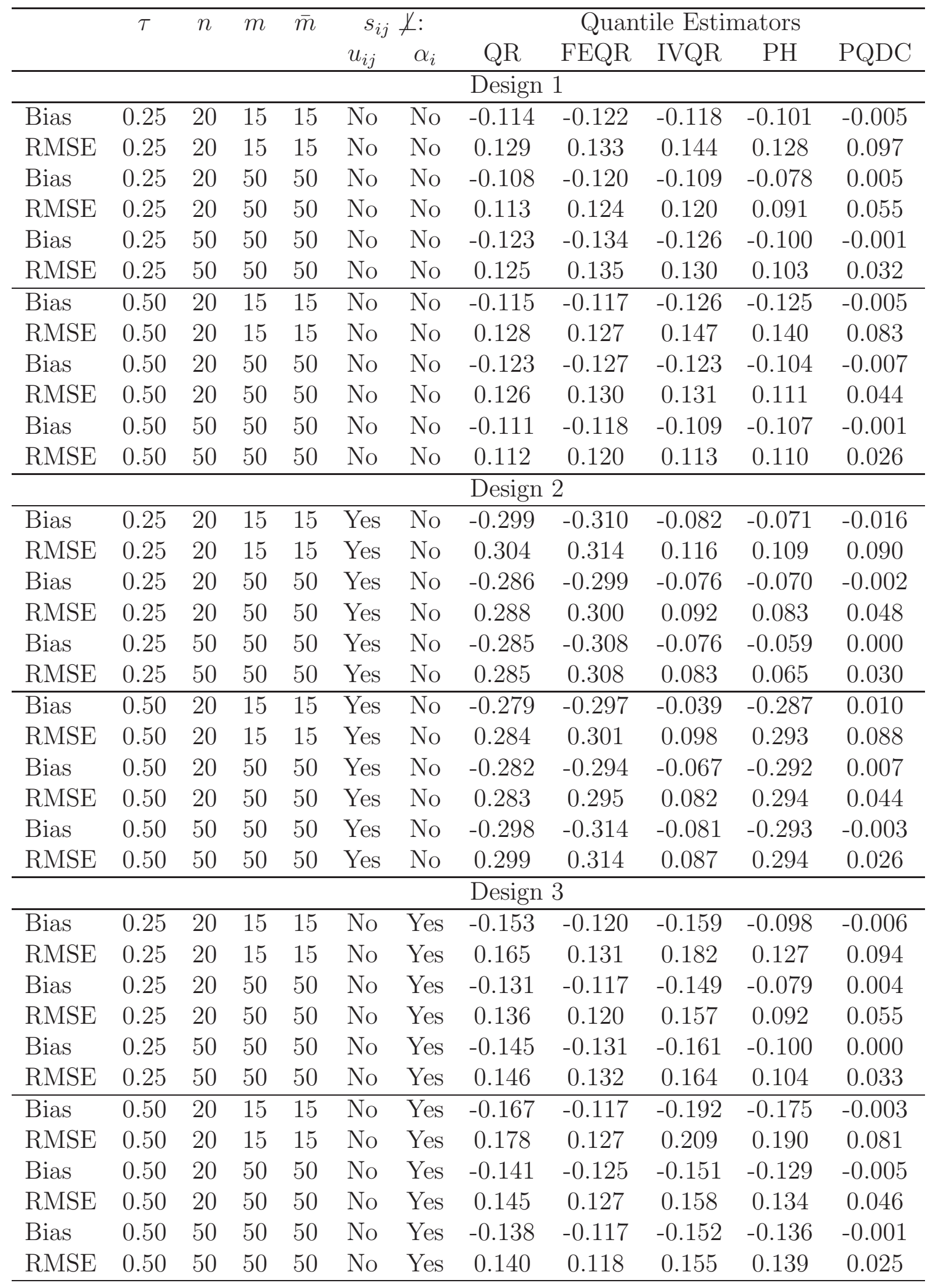

Table A.2: Monte Carlo results for Designs 1, 2 and 3 under fixed left- and right-censoring (double censoring). 


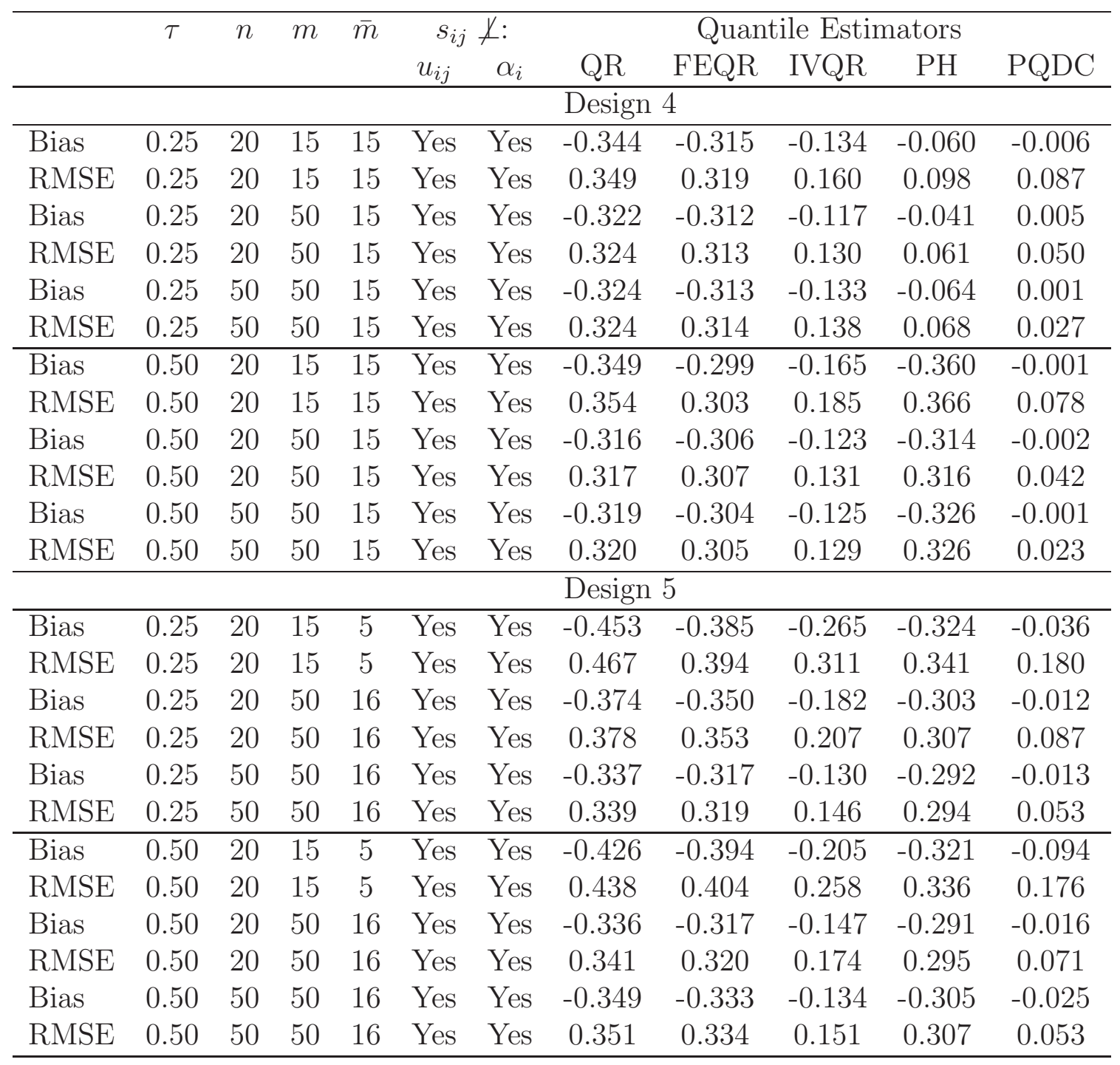

Table A.3: Monte Carlo results for Designs 4 and 5 under fixed left- and right- censoring (double censoring). 


\section{B Appendix B: Supplementary Tables}

\begin{tabular}{ll}
\hline \multicolumn{1}{c}{ Variables } & \multicolumn{1}{c}{ Description } \\
\hline Relative bid & Bid divided by the engineer's cost estimate \\
Relative winning bid & Winning bid divided by the engineer's cost estimate \\
Number of employees & This is the number of employees per establishment for a given month \\
Number of months in the market & This indicates the number of months survived during the sample period \\
Engineer cost estimate & Value of the engineer's cost estimate \\
Number of plan holders & Number of plan holders in an auction \\
Winning bid & The lowest bid on an awarded project \\
Complexity & The total number of bid items (project components) in a project \\
Active projects & Firm's projects that are still under construction \\
Complexity in active projects & Average number of bid items in active projects \\
Backlog & Constructed by summing across the incomplete \\
& value of the contract for ongoing projects \\
Capacity utilization & Project backlog divided by the maximum \\
Initial number of employees & backlog of that firm (or establishment) \\
Size & Number of employees at the initial month of entry \\
Highway cost index & Logarithm of total employment \\
(weighted sum of items) & Highway cost index is a composite indicator covering the unit costs \\
& of excavation, resurfacing, and construction, and reflects cost \\
changes for materials such as reinforcing steel, bituminous \\
concrete, portland cement and other ingredients for highway \\
projects across Texas counties \\
The cost index of the projects was obtained using the highway \\
Cost index of active & cost index $c_{t k}$ of different tasks $k$ provided by TxDOT. \\
projects & $\begin{array}{l}\text { The firm's weighted cost is } \bar{c}_{i t}=\sum_{k} \lambda_{i t k} c_{t k}, \text { where } \\
\text { Cingle-family building permits }\end{array}$ \\
The monthly unemployment rate in Texas \\
Number of single family units approved by the county for a given year \\
Indicators for asphalt paving projects, bridge, and other projects \\
including drainage and erosion control, concrete, traffic, etc. \\
Indicators for firms' entry year \\
\hline
\end{tabular}

Table B.1: Variable definitions. The data sources are: Texas Department of Transportation (TxDOT), Quarterly Census of Employment and Wages (QCEW) from Texas Workforce Commission, US Bureau of Labor Statistics, and US Bureau of Economic Analysis. 


\section{Appendix C: Additional Results}

In this section, we present additional results to evaluate the robustness of the excluded exogenous variables in the control function approach. The results are presented in Figure C.1. As in the previous figures, the quantiles of the conditional duration distribution are denoted by $\tau$. The continuous dotted lines show estimates obtained from the PQRC estimator proposed in this paper that uses the change in the number of single family units approved by building permits in a given year and number of plan holders in active projects as excluded exogenous variables to estimate the control function (IV Set 1). The shaded regions represent a 90 percent point-wise confidence interval. The other lines represent PQRC estimates using county unemployment rate before a plant enters the market and number of plan holders in active projects (IV Set 2) as excluded exogenous variables, and total volume of projects in Texas and number of plan holders in active projects (IV Set 3) as excluded exogenous variables. 

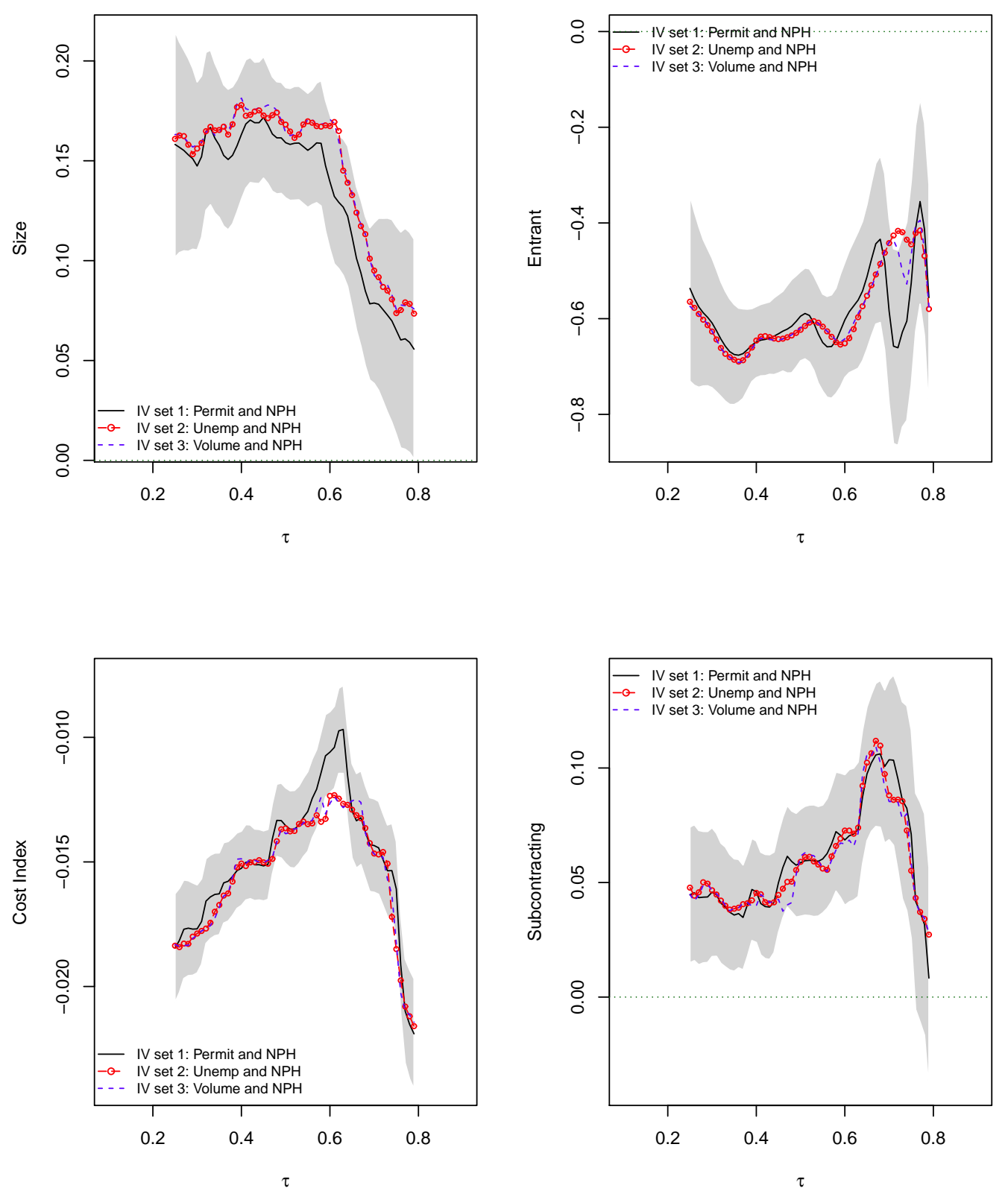

Figure C.1: Sensitivity of quantile regression results to the choice of the control variates. 